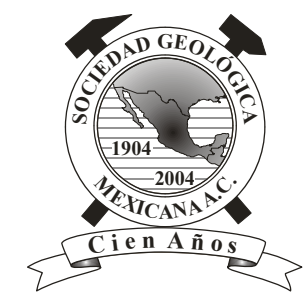

\title{
Patrimonio natural de la Reserva Ecológica del Pedregal de San Ángel y áreas cercanas: sitios de interés geológico y geomorfológico al sur de la Cuenca de México
}

\author{
José Luis Palacio Prieto ${ }^{1, *}$, Marie-Noëlle Guilbaud ${ }^{2}$ \\ ${ }^{1}$ Departamento de Geografía Física, Instituto de Geografía, Universidad Nacional Autónoma de México, Coyoacán, 04510, México \\ D.F., México. \\ ${ }^{2}$ Departamento de Vulcanología, Instituto de Geofísica, Universidad Nacional Autónoma de México, Coyoacán, 04510, México D.F., \\ México. \\ *palacio@unam.mx
}

\begin{abstract}
Resumen
La Reserva Ecológica del Pedregal de San Ángel (REPSA) es un territorio de conservación creado en 1983 dentro del campus de la Universidad Nacional Autónoma de México (UNAM). El objetivo de la REPSA es conservar un espacio de alto valor biológico y cultural, único en su género por la diversidad y características de la biota que sostiene, y que contiene los últimos reductos de ecosistemas naturales del sur de la Cuenca de México. Además del interés en los aspectos biológicos, la REPSA es un espacio geológica y geomorfológicamente significativo para explicar la evolución del paisaje de la porción sur de la Cuenca de México. En este trabajo se identificaron y caracterizaron nueve geositios (dentro y cercanos a la REPSA) ejemplares de los procesos volcánicos en esta zona de la Cuenca de México. El interés de los sitios seleccionados incluye valores estratigráficos (secuencias de lavas y piroclastos), geológicovulcanológicos (estructura de derrames de lavas, conos piroclásticos) y arqueológicos. Los sitios tienen también interés educativo, por lo que pueden incorporarse en esquemas de educación formal (como sitios de interés en cursos universitarios) e informales (como información para los visitantes no especializados) y contribuyen a la divulgación de las Ciencias de la Tierra, en particular de la geología y la geomorfología.
\end{abstract}

Palabras clave: geositios, volcán Xitle, Sierra Chichinautzin, patrimonio geológico, flujos de lava.

\begin{abstract}
The Pedregal de San Angel Ecological Reserve (PSAER) is a conservation area created in 1983 within the campus of the Universidad Nacional Autónoma de México (UNAM). The objective of the reserve is to maintain an area of biological and cultural diversity containing the last remnants of natural ecosystems in the southern Mexico Basin. The PSAER is also geologically and geomorphologically important in order to explain the evolution of the landscape of the southern portion of the Mexico Basin. This study identified and characterized nine geosites (in and near the PSAER) that are representative of regional volcanic processes. The interest of the selected sites includes volcano-stratigraphic (sequences of lavas and pyroclastics), volcanological (lava flows, pyroclastic cones) and archaeological features. The sites also have an educational value that can be incorporated into formal education schemes (as sites of interest in geology and geography courses) and informal uses (as information for non-specialized visitors) and contribute to outreach activities in the areas of Earth Sciences, particularly geology and geomorphology.
\end{abstract}

Keywords: geosites, Xitle volcano, sierra Chichinautzin, geological heritage, lava flows. 


\section{Introducción}

La Reserva Ecológica del Pedregal de San Ángel (REPSA) fue creada en octubre de 1983 en el campus central de la Universidad Nacional Autónoma de México (UNAM) ubicado en la zona sur de la Ciudad de México. Con una superficie original de $1.245 \mathrm{~km}^{2}$, la REPSA, cuenta hoy con poco más de $2.37 \mathrm{~km}^{2}$, aproximadamente la tercera parte del campus universitario. De la superficie total de la REPSA, 171 ha corresponden a la zona núcleo y 66 a la de amortiguamiento (Lot-Helgueras, 2008).

La creación de la REPSA en el campus de la UNAM se deriva del interés por conservar un espacio de "alto valor biológico y cultural... único en su género por la diversidad y características de la biota que sostiene, y que contiene los últimos reductos de ecosistemas naturales del sur del Valle de México" (www.repsa.unam.mx, consultado en julio de 2015).

Además del interés en los aspectos biológicos, la REPSA es un espacio geológica y geomorfológicamente significativo y representativo de la evolución del paisaje de la porción sur de la Cuenca de México. Se ubica sobre derrames de lava provenientes del volcán Xitle, que forma parte de la Sierra Chichinautzin, y cuyo origen y evolución han sido discutidos por diversos autores (Delgado et al., 1998; Siebe, 2000, entre otros). Toda vez que la mayor parte de los derrames lávicos referidos han sido absorbidos por la mancha urbana de la Ciudad de México, la REPSA corresponde a uno de los reducidos espacios naturales en donde las características geológicas y geomorfológicas pueden aún ser apreciadas. Así mismo, la REPSA brinda una serie de servicios ambientales fundamentales, en particular para el funcionamiento hidrológico de los mantos freáticos del sur de la Cuenca de México.

Los objetivos de la REPSA son análogos a los de cualquier Área Natural Protegida e incluyen la divulgación científica, la promoción de las ciencias naturales (ecología, biología) y de la Tierra (geología y geomorfología), entre otras, ya sea con fines educativos formales (como parte de un programa curricular reconocido) o informales (como parte de la información que se le brinda al visitante). Además, estas áreas son espacios para la investigación científica y pueden contribuir en el desarrollo local integral.

El objetivo de este trabajo es identificar y caracterizar sitios geológica y geomorfológicamente significativos que se ubican dentro de la REPSA y otros ubicados en sus alrededores, con el fin de contribuir a consolidar a la reserva como un espacio dedicado a la conservación, la educación, la investigación científica y la difusión de la cultura. Los sitios considerados constituyen un patrimonio natural cuya promoción contribuye, además, a la mejor comprensión de la evolución y relación con los elementos bióticos presentes en esta porción del sur de la Cuenca de México. El trabajo pretende, en suma, contribuir en la puesta en valor de los elementos abióticos (rasgos geológicos y geomorfológicos) presentes tanto en la REPSA como en sitios aledaños, que a la fecha han sido considerados y aprovechados marginalmente. Así mismo, pretende resaltar la importancia de la valoración del patrimonio geológico y geomorfológico y fomentar la realización de estudios similares en otras áreas de nuestro país.

\subsection{Geositios y geomorfositios}

Los geositios, también conocidos como sitios o puntos de interés geológico (ver por ejemplo Wimbledon et al., 2000; CSIGA, 2008) y geotopos (Wiedenbein, 1994) se refieren al componente geológico de la matriz abiótica de los ecotopos. Los geositios son una estrategia efectiva para proteger, valorar y promover a la geodiversidad, entendida como la diversidad de rasgos geológicos (rocas, minerales, fósiles), geomorfológicos (formas y procesos) y suelos, así como sus propiedades, relaciones y patrones espaciales; la geodiversidad representa los diferentes productos de la historia de la Tierra y de los procesos atmosféricos, así como sus interrelaciones con la biosfera y las actividades humanas (Gray, 2004). Desde el punto de vista conceptual, los geositios originalmente incluyeron no sólo a los sitios de interés geológico sino también a los de interés geomorfológico, debido a la estrecha relación que en muchos casos existe entre ambos. Panizza (2001) y Reynard y Panizza (2007), sin embargo, mencionan que los geomorfositios, a diferencia de los geositios, son formas de relieve que poseen un valor histórico, cultural, estético y/o socioeconómico. Para los efectos de este trabajo, los geositios y los geomorfositios son considerados de manera indistinta, si bien las descripciones enfatizan, en mayor o menor medida, ambas características.

\section{El área de estudio}

Los geositios seleccionados se encuentran asociados al derrame histórico de lava del volcán Xitle, que se ubica en la Sierra Chichinautzin, a unos cinco km al NE del volcán Ajusco y unos ocho al SW del campus de la UNAM (Figuras 1 y 2). Una característica de este derrame se asocia con la mancha urbana que hoy constituye la Ciudad de México. Ya los primeros asentamientos humanos vieron en este derrame lávico una fuente de material para la construcción. El proyecto constructivo de la Ciudad Universitaria, desde finales de la década de 1940, implicó la explotación del derrame para la extracción de rocas y la construcción de una buena parte de la infraestructura del campus. Por ello, existen numerosos cortes (canteras) de grandes dimensiones que permiten apreciar la estructura interna del derrame y contactos con el terreno original, lo que, en este caso, representa una oportunidad para la identificación de algunos de los sitios de interés que aquí se consideran. Se identificó un total de nueve sitios, de los cuales seis se encuentran dentro del campus de la Ciudad Universitaria de la UNAM (cuatro de ellos dentro de la REPSA y dos fuera de sus 

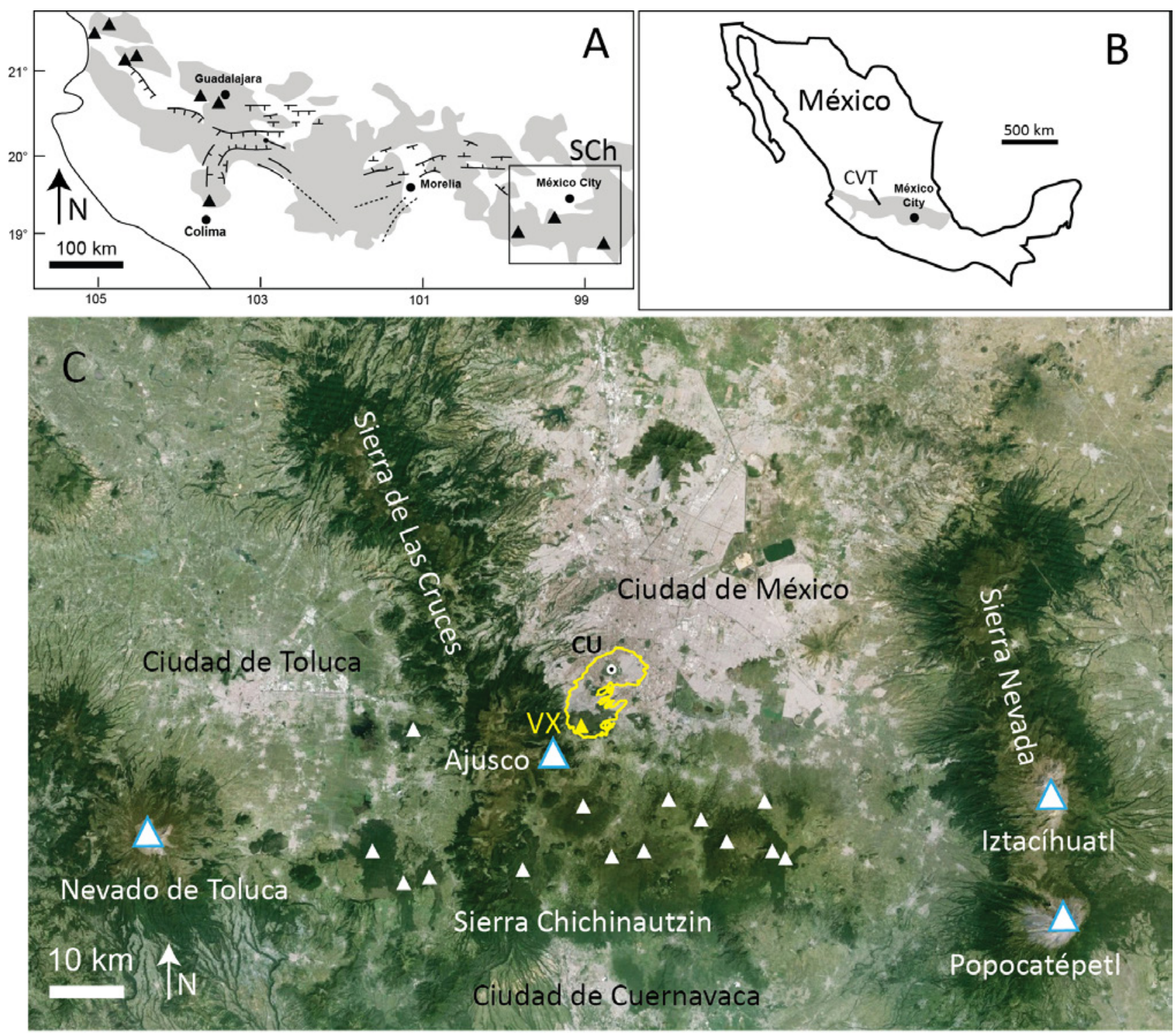

Figura 1. A. Ubicación de la Sierra Chichinautzin ( $\mathrm{SCh}$ ) dentro del Cinturón Volcánico Transversal (en gris claro). Los triángulos negros corresponden a los principales estratovolcanes de la región. B. Ubicación del Cinturón Volcánico Transversal (CVT) en México. C. Ubicación del Volcán Xitle (VX) y derrames asociados (línea amarilla) en relación con la Sierra Chichinautzin (volcanes recientes en triángulos blancos). CU: Ciudad Universitaria. La imagen fue tomada de Google Earth (imagen obtenida en septiembre 4 de 2013, consultada en línea en agosto de 2015).

límites) y tres se encuentran fuera del campus (Pirámide y Centro Comercial de Cuicuilco, Bosque de Tlalpan y el volcán Xitle; Figura 2). En todos los casos, los sitios son de fácil acceso, salvo algunas restricciones menores que se señalan en cada caso.

\subsection{Contexto geológico}

La Sierra Chichinautzin ( $\mathrm{SCh}$ ) es un campo volcánico ubicado en la porción central del Cinturón Volcánico Transversal (CVT), mismo que, con una dirección general oeste-este, cruza a México entre los $19^{\circ}$ y los $20^{\circ}$ de latitud norte, desde el océano Pacífico hasta el Golfo de
México (Figura 1). La SCh está compuesta por más de 220 pequeños edificios volcánicos (principalmente conos de escoria) y derrames lávicos cuaternarios asociados con secuencias de tefra y depósitos aluviales que cubren una extensión aproximada de $2340 \mathrm{~km}^{2}$ (Swinamer, 1989). La mayor parte de las rocas de la SCh corresponden a andesitas, andesitas basálticas y dacitas, que definen una serie calcialcalina (Swinamer, 1989; Wallace y Carmichael, 1999; Siebe et al., 2004; Schaaf et al., 2005). Desde el punto de vista geomorfológico, los edificios volcánicos y derrames lávicos asociados mantienen sus formas originales, lo que se deriva de su relativa juventud y al consecuente escaso trabajo erosivo sobre ellas. El Xitle, ubicado en la porción norte de la $\mathrm{SCh}$ es considerado como el volcán más joven 


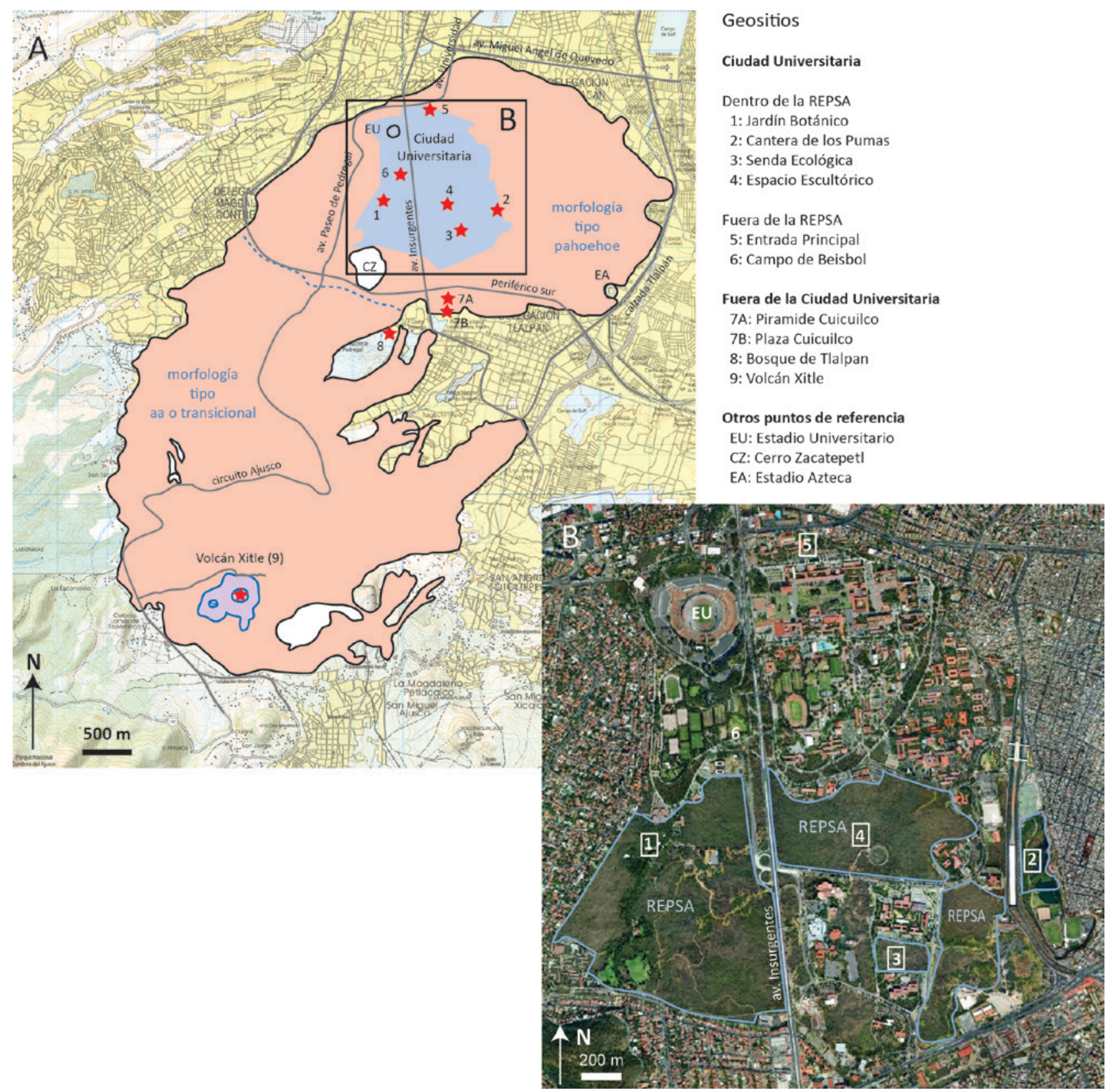

Figura 2. Derrame lávico del volcán Xitle y ubicación de geositios y otros puntos de referencia. A. Límites del derrame (en rosa) sobre mapa topográfico editado por el INEGI en escala 1:50000. Las zonas urbanizadas aparecen en amarillo en el mapa topográfico. La línea punteada azul nota la ubicación aproximada del límite entre lavas de tipo pahoehoe y lavas de tipo $a a$ o transicional entre estos dos tipos. Las estrellas en color rojo indican la ubicación de los geositios identificados en este trabajo. B. Ubicación de geositios dentro de la Ciudad Universitaria (imagen satelital de Google Earth obtenida en septiembre 4 de 2013, consultada en línea en agosto de 2015).

de la zona; su edad ha sido estimada en aproximadamente 1670 AP (Siebe, 2000). La edad de la erupción del Xitle ha sido motivo de discusión; las edades atribuidas a la misma, establecidas a través de datación con radiocarbono, muestran una gran variabilidad, de hasta 1000 años entre ellas, lo que se deriva principalmente de las condiciones de muestreo (Siebe, 2000). Cabe mencionar que la primera edad publicada aparece en el primer listado de fechas obtenidas por la técnica de fechamiento por radiocarbono (Libby, 1955).
El Xitle es un cono de escoria que culmina a 3150 msnm (altura desde la base de $140 \mathrm{~m}$ ), ubicado sobre la ladera noreste del volcán Ajusco, cuya cima alcanza los $3950 \mathrm{msnm}$; sus flujos lávicos discurren con dirección general hacia el norte, llegando a 12 ó $13 \mathrm{~km}$ de distancia del centro emisor, cubriendo una superficie total de $70 \mathrm{~km}^{2}$ aproximadamente (Delgado et al., 1998). Las lavas son andesitas basálticas, ricas en álcalis, y contienen cristales de olivinos, plagioclasas y clinopiroxenos (Wallace y Carmichael, 1999). Las estructuras internas de las lavas, 
expuestas en diversas canteras y cortes en su frente, han sido descritas en el siglo anterior (Waitz y Wittich, 1910; Wittich, 1919; Schmitter, 1953; Badilla-Cruz, 1977), pero algunas de las interpretaciones de estos autores han sido revisadas por Walker $(1993,2009)$. En particular, algunas estructuras recurrentes en las lavas han sido asociadas a la interacción explosiva entre la lava y agua en el subsuelo, los llamados "tubos de explosión" de Waitz y Wittich (1910), pero Walker (2009) interpreta como zonas de suturas entre flujos contiguos (ver Figura 7: sitio Entrada Principal - CU). Cabe mencionar que las propiedades magnéticas y paleomagnéticas de las lavas han sido estudiadas extensivamente (Herrero-Bervera et al., 1986; Cañón-Tapia et al., 1995 y 1996; Alva-Valdivia, 2005; Morales et al., 2006).

Aunque la actividad del volcán fue dominantemente efusiva, también produjo una cantidad importante de cenizas, preservadas hasta varios kilómetros del cono principal (Martin del Pozzo, 1982; Cervantes y Molinero, 1995; Delgado et al., 1998; Siebe, 2000; González et al., 2000). En la zona próxima al cono, estos depósitos forman una secuencia estratificada de ceniza fina a lapilli que se encuentra estratigráficamente tanto debajo como encima de las lavas proximales, indicando al menos dos episodios explosivos. En partes distales del campo de lava, una capa de ceniza fina de menos de $5 \mathrm{~cm}$ de espesor ha sido encontrada debajo de las lavas (ver figuras 7 y 8 en descripción de sitios CEPE-entrada principal y Campo de Beisbol), probablemente resultado de un episodio explosivo temprano. Cabe señalar que no existe todavía una reconstrucción completa de la compleja historia eruptiva del volcán.

\subsection{Características morfológicas de las lavas}

Las lavas del Xitle presentan distintas morfologías, las cuales varían con la distancia a la fuente y la pendiente original del terreno (Figura 2). En partes proximales y mediales sobre pendientes entre $2^{\circ}$ y $7^{\circ}$, la superficie de la lava es fragmentada, de tipo $a a$ (ver MacDonald, 1953) y el interior de los flujos, expuesto en cortes a lo largo de la carretera Picacho-Ajusco, es masivo y presenta vesículas irregulares. En la parte distal, emplazadas sobre un terreno plano $\left(<2^{\circ}\right.$, zona de la Ciudad Universitaria), las estructuras de las lavas son características de lavas de tipo pahoehoe. Los términos de pahoehoe y a a provienen de las islas hawaianas, donde estas estructuras lávicas son comunes y han sido extensamente estudiadas, particularmente durante la erupción actual del volcán Kilauea (Kauahikaua et al., 2003). En comparación con las lavas $a a$, las lavas pahoehoe tienen una superficie lisa, localmente encordada, y un interior vesicular (MacDonald, 1953). Este tipo de morfología es típico de lavas con baja viscosidad, con composición basáltica o andesítica-basáltica, tal como es el caso de las lavas del Xitle. Las lavas de tipo pahoehoe son poco comunes dentro del Cinturón Volcánico Transversal mexicano ya que el contexto tectónico de subducción continental favorece la erupción de lavas con mayor contenido en sílice y mayor viscosidad (andesitas). Las lavas del Xitle son entonces morfológicamente peculiares dentro del Cinturón Volcánico Mexicano.

\subsection{Antecedentes históricos}

\subsubsection{Cuicuilco}

Cuicuilco es considerado uno de los primeros centros urbanos en la Cuenca de México, cuya máxima complejidad se ha fijado en el preclásico tardío (150 - 50 a.C.; Parsons, 1989). Por la presencia de grandes estructuras arquitectónicas, se le ha considerado, junto con Teotihuacán, uno de los centros urbanos regionales más importantes de la Cuenca de México (Sanders et al., 1979). El desarrollo de Cuicuilco tuvo lugar sobre una planicie deltaica, formada por los ríos provenientes del volcán Ajusco (Córdova et al., 1994; Siebe, 2000), la que fue posteriormente cubierta por las lavas del volcán Xitle.

Uno de los aspectos que ha despertado mayor interés se refiere al abandono del sitio. En este sentido, dos hipótesis han sido planteadas. La primera de estas hipótesis sugiere que el abandono se produjo como resultado del desarrollo alcanzado por Teotihuacán, ubicado en la parte norte de la Cuenca de México, que absorbió gran parte de la población en la región. La segunda hipótesis atribuye el abandono de Cuicuilco directamente a la devastación causada por la erupción del Xitle.

La primera hipótesis está basada en evidencias arqueológicas que ubican la decadencia de Cuicuilco hacia el 150 d.C. Además, existe evidencia de que los monumentos en el sitio mostraban un avanzado deterioro antes de ser cubiertos por la lava del Xitle, lo que indicaría que el sitio había sido ya abandonado en el momento de la erupción (Heizer y Bennyhoff, 1958). Córdova et al. (1994) están a favor de esta hipótesis, basados en la existencia de depósitos detríticos expuestos durante las primeras excavaciones en Cuicuilco, originados por la acumulación de materiales provenientes de la degradación de las estructuras arquitectónicas. También, el fechamiento de carbón presente en la ceniza del mismo volcán implica que la erupción ocurrió 300 años más tarde que lo que previamente se pensaba, cuando las poblaciones habían ya migrado a Teotihuacán (Siebe, 2000). Sin embargo, considerando estos nuevos datos y nuevas excavaciones alrededor de la pirámide principal, González et al. (2000) apoyan a la invasión por las lavas de un área en uso, y concluyen en la influencia directa de la erupción sobre el abandono del sitio. En conclusión el debate sobre estas dos hipótesis sigue abierto, y probablemente podrá ser aclarado mediante futuras excavaciones.

\subsubsection{Ciudad Universitaria}

La Ciudad Universitaria (CU) es la sede principal de la Universidad Nacional Autónoma de México (UNAM). En 
1943, se eligió el sitio adecuado para construir la Ciudad Universitaria: el Pedregal de San Ángel, zona de terrenos predominantemente volcánicos, producto de erupciones de varios volcanes, entre ellos el Xitle. El campus fue inaugurado oficialmente el 20 de noviembre de 1952 , luego de cuatro años de haberse iniciado el proceso de construcción, aunque sus actividades comenzaron hasta marzo de 1954. El objetivo central de la construcción de la CU era agrupar en un espacio común a las escuelas que ocupaban diferentes edificios ubicados el centro de la Ciudad de México.

\section{Sitios de interés geológico y geomorfológico de la REPSA y áreas circundantes}

Los sitios de interés geológico y geomorfológico identificados en este trabajo fueron seleccionados con base en su representatividad y su relación con valores adicionales que incluyen aspectos arqueológicos, ecológicos, hidrológicos, estéticos, históricos y/o culturales. Todos los sitios son de fácil acceso, condición que favorece su uso para fines educativos, turísticos y de promoción del patrimonio natural geológico y geomorfológico en general. Como ya se ha señalado, se incluyen en esta caracterización, además de sitios ubicados dentro de la REPSA, algunos cercanos fuera de la misma, los cuales se encuentran relacionados con las lavas presentes en la reserva y explican la evolución geológica de esta porción de la Cuenca de México. Se hace énfasis particular en las características vulcanológicas observadas (principalmente referentes a las lavas) y se describen los procesos que les dieron origen, haciendo referencia a algunos trabajos recientes en esta materia. En varias partes, se destacan las implicaciones que estas observaciones tienen sobre el estilo de la erupción o la evaluación de riesgos. La descripción de los sitios se llevó a cabo mediante la elaboración de una ficha técnica que sintetiza sus características; su ubicación se presenta en la Figura 2.

3.1. Geositios ubicados en el campus de Ciudad Universitaria dentro de la REPSA

ID 1: Lavas pahoehoe del Jardín Botánico

Ubicación: Parte central-oeste de la Ciudad Universitaria, contiguo al Instituto de Biología

Coordenadas geográficas: $19^{\circ} 19^{\prime} 11.1^{\prime \prime} \mathrm{N}$ y $99^{\circ} 11^{\prime} 35.0^{\prime \prime} \mathrm{W}$ Altitud: $2317 \mathrm{msnm}$.

Acceso: Por la entrada del Instituto de Biología, Circuito exterior. La entrada al jardín está controlada por medio de un puesto de vigilancia. El horario de visita es de 9 a 16.30 horas todos los días, excepto días festivos y durante los periodos vacacionales de la UNAM. Cuenta con servicio de visitas guiadas orientadas a los aspectos botánicos.

\section{Interés y valores:}

- Vulcanológico: estructuras y texturas de superficie de lavas de tipo pahoehoe.

- Botánico: lugar de exposición y conservación de gran variedad de plantas.

- Estético: área verde con arreglo de zonas de plantación. Descripción: A cargo del Instituto de Biología y fundado en 1959, el jardín botánico de la UNAM está considerado el más grande de América Latina, con una alta diversidad de plantas expuestas al público en un jardín exterior de 7 hectáreas. La misión general del jardín es de "investigar la utilización, el manejo y los valores culturales de la flora mexicana en general y de algunas familias botánicas en particular", así como de "promover la conservación in situ y ex situ de las plantas basada en la investigación y difundir el conocimiento a la sociedad y la comunidad académica" (www.ibiologia.unam.mx/jardin/, consultado en julio de 2015).

El jardín se establece sobre las lavas del volcán Xitle; el recorrido permite observar varias estructuras típicas de la parte distal de las coladas de lava (Figura 3A). Se puede observar la superficie vesicular, lisa, continua y localmente encordada de las lavas (Figuras 3B, 3C), característica principal de las lavas de tipo pahoehoe (MacDonald, 1953). Puede observarse también que las lavas forman pequeños domos o escudos de decenas de metros de largo y ancho, y hasta varios metros de alto (Figura 3C). Estas estructuras, llamadas hummocks (MacDonald, 1953), tumuli, o lava rises (Walker, 1991), se forman por la deformación y el levantamiento de la superficie del flujo debido a la inyección de lava fluida en su interior (proceso de "inflación", Hon et al., 1994 y Self et al., 1998). La resistencia de la corteza superior sólida a la expansión del flujo resulta en la formación de grietas profundas en forma de $\mathrm{V}$ (lava inflation cleft) que se propagan dentro de la corteza durante su crecimiento (Figura 3C). Estas fracturas abiertas subdividen la superficie de la lava en placas inclinadas. Dentro del jardín, se han acondicionado caminos con escalones, que permiten seguir este tipo de fracturas que alcanzan hasta $2 \mathrm{~m}$ de profundidad. La corteza superior expuesta en las grietas es rica en vesículas, que son pequeñas oquedades en la roca derivadas de las burbujas atrapadas dentro de las lavas durante su enfriamiento. Estas vesículas son aquí típicamente alargadas, e incrementan en tamaño mientras disminuyen en densidad hacia el interior del flujo. En varias partes del jardín se observa la deformación del interior de los flujos en láminas incurvadas que se propagan desde el interior del flujo hacia un flujo contiguo (Figura 3B). Mal entendido todavía, este tipo de formación se ha relacionado con el crecimiento interno de flujos en un campo de lava pahoehoe emplazado sobre un terreno poco inclinado (Walker, 2009; ver también sitio Entrada Principal - zonas de suturas).

Otro aspecto de interés del jardín botánico reside en la observación del desarrollo de las plantas que crecen directamente sobre el substrato rocoso, aprovechando las múltiples grietas que se formaron durante el enfriamiento de la lava (Figura 3D). Así mismo se observan los primeros 

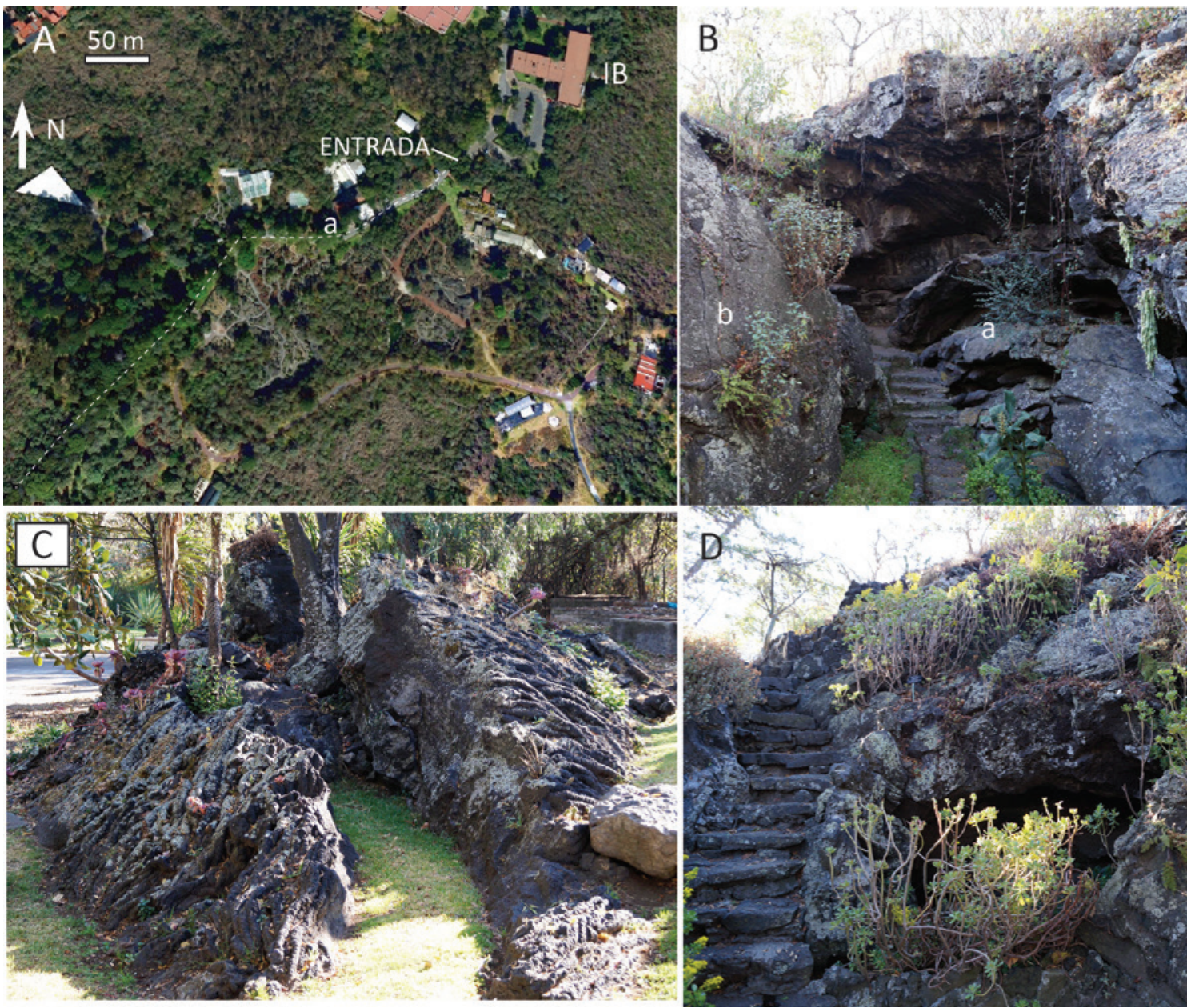

Figura 3. Sitio Jardín botánico (ID 1). A. Ubicación del sitio próximo al Instituto de Biología (IB) en imagen satelital (Google Earth, obtenida en septiembre 4 de 2013, consultada en línea en agosto de 2015). El camino principal (a) corresponde a la línea blanca punteada. El jardín se ubica en el límite entre dos flujos de lava contiguos, los afloramientos de lavas a los cuales el texto se refiere se ubican justo al sur del camino principal y son accesibles por caminos empedrados. B. Estructura de deformación del interior de un flujo (a) relacionado con la presencia de un lóbulo contiguo (b). Nótese la superficie lisa del lóbulo b. C. Estructura de tumulus con fracturas abiertas y superficies cordadas (lava pahoehoe). D. Crecimiento de plantas sobre superficie de lava.

pasos en el desarrollo de vegetación sobre un sustrato rocoso, en principio poco favorable para la colonización vegetal.

Finalmente, en este sitio se observa cómo se utilizan fragmentos de roca volcánica piroclástica tipo escoria (conocida localmente como tezontle) para cubrir el terreno alrededor de las plantaciones, permitiendo mantener una buena irrigación de la planta (por la porosidad del material) evitando el crecimiento de maleza y mejorando el aspecto estético. Esta técnica es comúnmente usada en la ciudad de México, donde abunda este tipo de escoria.

Conservación: El estado de mantenimiento y conservación de este sitio es muy bueno, dado su uso como centro de exposición, conservación e investigación biológica. Presenta algunas medidas de acondicionamiento favorables a la observación de estructuras lávicas, en particular caminos empedrados. El interés geológico y geomorfológico del sitio está, sin embargo, poco valorizado y promovido.
ID 2: Lavas y manantiales de la Cantera de los Pumas Ubicación: Cantera oriente al sur-este de Ciudad Universitaria, terreno de $206000 \mathrm{~m}^{2}$; la porción norte de esta cantera corresponde a la REPSA y en el sur se encuentran las instalaciones deportivas del equipo de futbol representativo de la UNAM, inauguradas en 1996 (Figura 4).

Coordenadas geográficas: $19^{\circ} 18^{\prime} 50.76^{\prime \prime} \mathrm{N}$ y $99^{\circ} 10^{\prime} 16.67^{\prime \prime}$ W

Altitud: 2277 msnm.

Acceso: Se accede por la calle Totonacas a un costado de la avenida Aztecas, cerca de su cruce con avenida del IMAN, al sureste del campus. Se recomienda hacer cita para acceder al sitio.

\section{Interés y valores:}

- Geológico: corte de18 a $35 \mathrm{~m}$ de lava, llegando localmente a la base del derrame.

- Hidrológico: presencia de manantiales surgiendo en la base de las lavas; formación de encharcamientos de profundidad variable a lo largo del año y cuerpos de 
agua permanentes.

- Histórico: la piedra extraída de la cantera fue usada para construir a la Ciudad Universitaria (Gaitán-Martínez, 2012).

- Estético y paisajístico: zona verde bien mantenida y aislada del ruido de la ciudad.

Descripción: El principal interés geológico de este sitio es la exposición de la organización vertical y lateral de los flujos de lava provenientes del volcán Xitle. Es el más extenso y espeso corte vertical de lava del Xitle existente a la fecha. En las paredes de la cantera se observa la superposición vertical de varias unidades de lava, aquí llamados lóbulos
(Figura 4C). Cada lóbulo se define por una corteza vesicular de color rojo en las paredes que rodea un núcleo denso de color gris (Figuras 4C, 4D). La corteza superior representa poco menos de la mitad del espesor total del lóbulo mientras que la corteza inferior es más delgada $(<30 \mathrm{~cm})$ y poco desarrollada en la base de flujos espesos (Figura 4C). En las paredes de la cantera, los lóbulos varían desde $10 \mathrm{~cm}$ hasta algunos metros en espesor y tienen superficies desde plana (sheet lobes) hasta bombeada (hummocky lobes) (Figura 4C). La superficie cordada de la base y la cima de los flujos aparece en varios sitios (Figura 4D y 4E). En varias partes el contacto vertical entre dos flujos está marcado por una
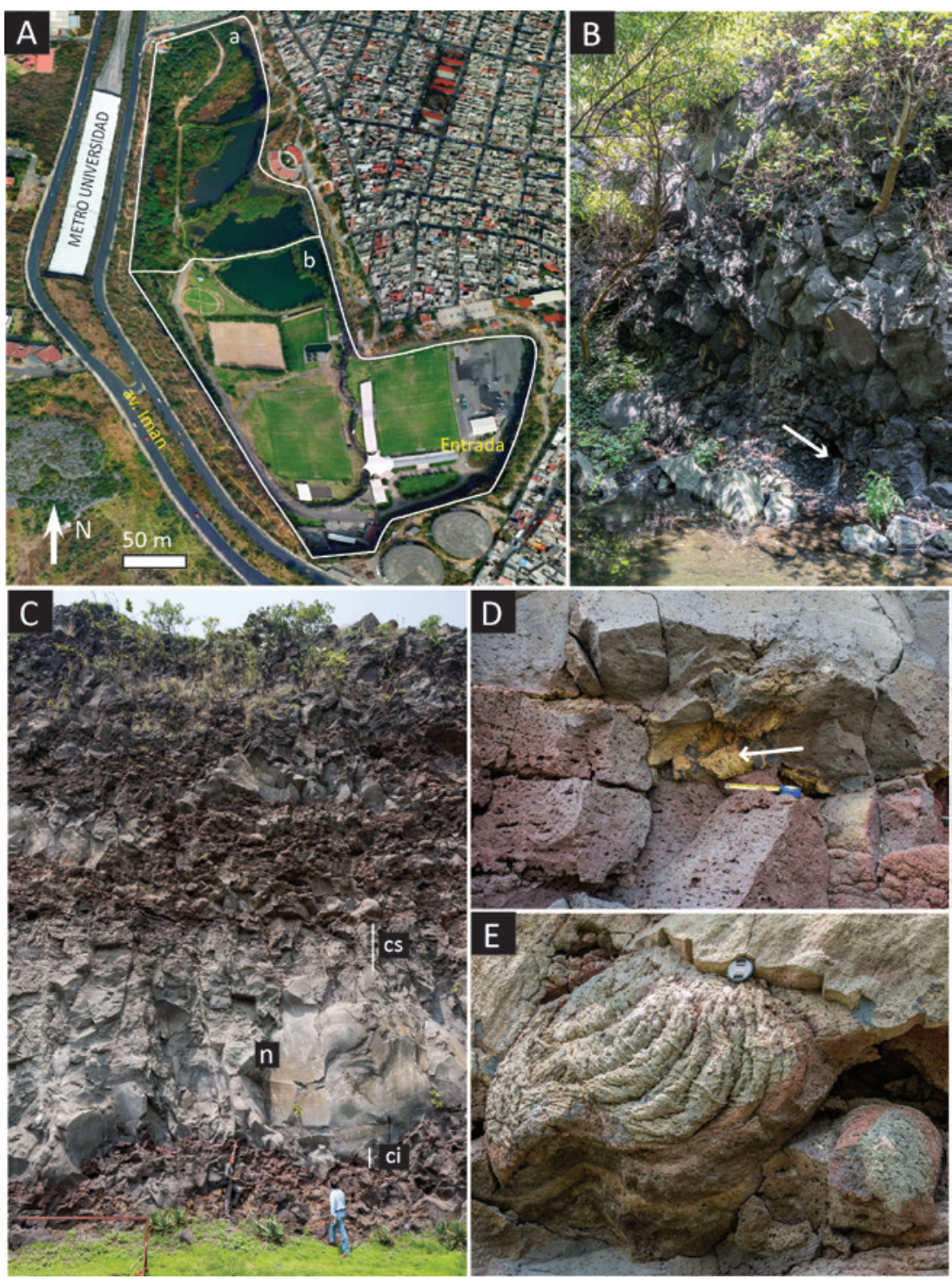

Figura 4. Sitio Cantera de los Pumas (ID 2). A. Límites de la zona de interés en imagen satelital (Google Earth, obtenida en septiembre 4 de 2013, consultada en línea en agosto de 2015). La porción norte de la cantera (a) corresponde a la REPSA, la sur (b) a instalaciones deportivas. Nótese la presencia de lagos en la parte norte, los que son alimentados por manantiales (B) que surgen de la base de los flujos lávicos (flecha) C. Vista de la pared oeste de la cantera; el núcleo denso de los flujos $(\mathrm{N})$ aparece de color gris claro mientras su parte superior vesicular (Cs) es rojiza. La corteza inferior vesicular (Ci) es poco desarrollada en el lóbulo de mayor espesor. La secuencia de flujos se compone de flujos pequeños $(<1 \mathrm{~m}$ de espesor) en la parte basal cubierto por un flujo más importante (aproximadamente $5 \mathrm{~m}$ de espesor) con una base irregular y una superficie plana, cubierta por una secuencia de lóbulos de menor espesor y dominado por superficies vesiculares fracturadas. D. Detalle del contacto vertical entre dos lóbulos; nótese la corteza vesicular rojiza y fracturada del lóbulo inferior, y la base cordada y de color amarillo del lóbulo superior (flecha). E. Superficie cordada y colorida de un pequeño lóbulo de lava. 
coloración amarilla-verdosa-rojiza de la lava, lo cual resulta de la acumulación de gases que escaparon del interior del flujo inferior durante su enfriamiento (Figuras 4D y $4 \mathrm{E}$ ). La falta de paleosuelo entre las diferentes unidades, así como la presencia de zonas de fusión o zonas de suturas entre ellas (zonas de contacto entre dos lóbulos emplazados al mismo tiempo, ver sitio Entrada principal CU) indican que los flujos se emplazaron durante un mismo episodio eruptivo. La organización compleja de los flujos sugiere bajas, así como fluctuantes tasas de emisión de lava, lo que favorece la formación de múltiples unidades de flujo y no una sola. Sin embargo, el espesor importante de la sucesión (hasta $40 \mathrm{~m}$ ) implica una larga duración de abastecimiento en lava fluida ( $>7$ años considerando las tasas de crecimiento de las lavas actuales del volcán Kilauea; Guilbaud y Siebe, 2009). La presencia de cuerpos de agua en este sitio no sólo contribuye en su aspecto estético sino también tiene un interés científico ya que son abastecidos por manantiales de agua fría (agua meteórica) que surgen de la base de los flujos (Figura 4B). Esta característica demuestra las propiedades hidrológicas de las coladas.

Conservación: Este sitio puede dividirse en dos partes (Figura 4A). La primera de ellas corresponde a su porción norte, que se destina fundamentalmente a la conservación y forma parte de la REPSA. La parte sur corresponde a los campos de entrenamiento e instalaciones deportivas del equipo de futbol Pumas de la UNAM. El acceso controlado y el uso a que se destina permiten conservarlo en buen estado, y sobre todo libre de un desarrollo urbano que podría llegar a ocultar las paredes de lava, como ha ocurrido en los alrededores. Cabe resaltar que la parte distal del campo de lava del Xitle que cubre desde la UNAM hasta la parte sur de la calzada Tlalpan (desde la avenida Miguel Ángel de Quevedo hasta el Estadio Azteca) ha sido intensamente explotada aunque la mayoría de las canteras han desaparecido por el acelerado desarrollo urbano.

\section{ID 3: Senda Ecológica \\ Ubicación: Parte sur-oeste del campus. \\ Coordenadas geográficas: $19^{\circ} 18^{\prime} 44.7^{\prime \prime} \mathrm{N}$ y 99 $90^{\circ} 10^{\prime} 52.1^{\prime \prime} \mathrm{W}$ Altitud: $2328 \mathrm{msnm}$. \\ Acceso: Entrada por el estacionamiento norte de Universum, Museo de las Ciencias de la UNAM. \\ Interés y valores: \\ - Vulcanológico: estructuras superficiales de lavas. \\ - Ecológico: desarrollo vegetal y animal sobre lavas. \\ - Geodésico: estación GPS de la UNAM.}

Descripción: Este sitio ofrece un paseo sobre los flujos de lava, siguiendo una escultura en roca y cemento que representa una serpiente. La cabeza de la serpiente aparece al inicio del camino (a en Figura 5A, Figura 5B), mientras su cuerpo se aprecia a lo largo del mismo. En todo el recorrido, se observa la superficie de los flujos y su compleja organización en diversas unidades de diferentes tamaños. Las grietas abiertas en forma de " $V$ " que separan la superficie vesicular de los flujos, resultan de la deformación

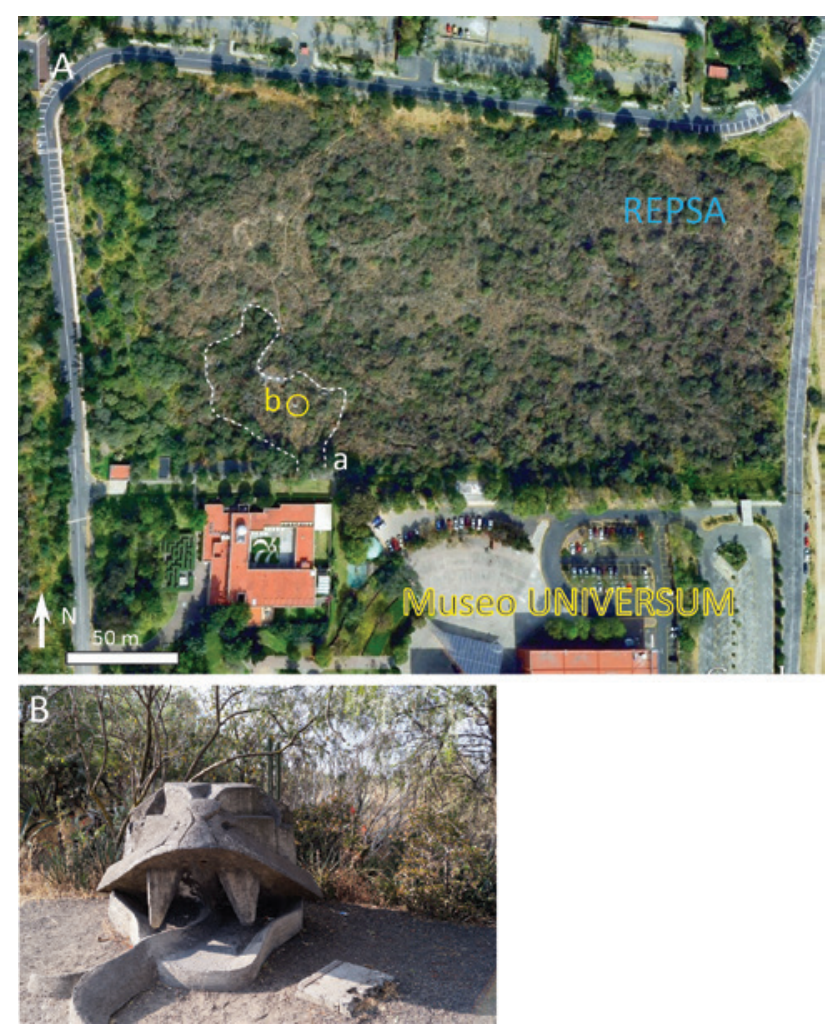

Figura 5. Sitio Senda ecológica (ID 3). A. Ubicación de recorrido (línea blanca punteada), punto de inicio de éste (a), antena GPS (b) y Universum al sur en imagen satelital (Google Earth, obtenida en septiembre 4 de 2013, consultada en línea en agosto de 2015). B. Monumento al inicio del recorrido.

de la corteza durante procesos de inflación (ver descripción más extensa en sitio Jardín Botánico).

El carácter ecológico del recorrido radica en la observación de la diversidad de la fauna y flora silvestres que prevalecen sobre el pedregal. La superficie irregular de las lavas así como la multitud de grietas, proveen condiciones favorables para el crecimiento de diversas plantas y presencia de animales (principalmente aves, reptiles y mamíferos).

En este sitio se puede también ver una columna de $4.5 \mathrm{~m}$ de alto con un domo en su cima, que corresponde a una estación GPS (Global Positioning System) del Departamento de Sismología del Instituto de Geofísica de la UNAM (b en Figura 5A). Anclado en la roca, este equipo registra continuamente la elevación del terreno con una precisión milimétrica. Estos datos son utilizados para el estudio de la deformación de la corteza terrestre en esta porción del país. Conservación: El camino es transitable pero los señalamientos originalmente instalados para la observación de la fauna y flora se encuentran muy deteriorados, no faltan las evidencias de perturbación y la acumulación de basura. Se destaca sin embargo la organización por parte de Universum de días dedicados a la recolección de basura (consultar: http://www.universum.unam.mx). 
ID 4: Espacio escultórico

Ubicación: A un costado del circuito exterior, Ciudad Universitaria, cerca de la zona cultural.

Coordenadas geográficas: $19^{\circ} 19^{\prime} 06.8^{\prime \prime} \mathrm{N}$ y $99^{\circ} 10^{\prime} 55.2^{\prime \prime} \mathrm{W}$ Altitud: $2310 \mathrm{msnm}$.

Acceso: Por una senda pavimentada; acceso controlado en horario de 9 - 18 hrs., entre semana únicamente.

\section{Interés y valores:}

- Vulcanológico: superficies de lava bien expuestas.

- Cultural y Social: centro de reunión y de eventos sociales en la universidad.

- Estético: arreglo escultural y vista a los volcanes.

Descripción: Inaugurado el 23 abril 1979 en la parte suroeste de CU, el espacio escultórico "geometrista" consiste en una estructura circular de $120 \mathrm{~m}$ de diámetro exterior, en cuyo perímetro se encuentra un conjunto de 64 bloques de cemento divididos en cuatro grupos, que rodean un campo de lava (Figura 6A). Representa una zona con importantes valores culturales, arquitectónicos y estéticos (De Kassner, 2009). Las lavas allí expuestas forman secuencias de lóbulos inter-conectados con superficie localmente fragmentada y deformada de apariencia viscosa. El interés vulcanológico

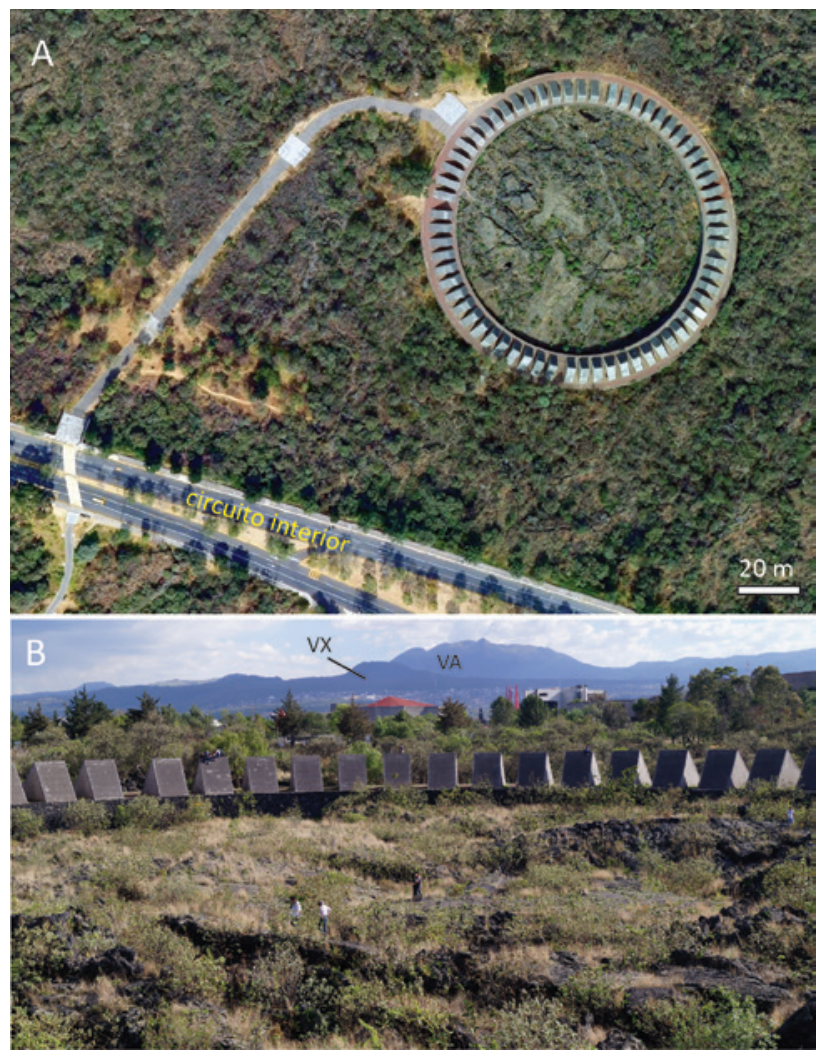

Figura 6. Sitio Espacio escultórico (ID 4). A. Vista de la estructura y el camino de acceso en una imagen satelital (Google Earth, obtenida en septiembre 4 de 2013, consultada en línea en agosto de 2015). B. Vista desde la parte superior de un bloque de cemento ubicado en la parte noroeste de la estructura. Se aprecia el volcán Xitle (VX) y el estravolcán extinto del Ajusco (VA) al fondo. Estos dos volcanes están construidos sobre la meseta elevada de la Sierra Chichinautzin. principal del sitio consiste en la posibilidad de caminar directamente sobre la lava y observar la textura rugosa de su superficie, así como la organización compleja de los flujos. En otros sitios estas características se encuentran cubiertas por la vegetación. En días con buena visibilidad, se alcanzan a apreciar los volcanes Xitle y Ajusco desde este sitio, ubicados al sur-suroeste (Figura 6B).

Conservación: El lugar está en buen estado de conservación aunque no falta la presencia de basura dejada por los visitantes.

\subsection{Geositios ubicados en el campus de Ciudad} Universitaria fuera de la REPSA

ID 5: Cortes de lava de la entrada principal de Ciudad Universitaria y paleosuelo en el Centro de Enseñanza para Extranjeros (CEPE)

Ubicación: Entrada principal (norte) de Ciudad Universitaria, sobre la avenida Universidad.

Coordenadas geográficas: $19^{\circ} 20^{\prime} 08.5^{\prime \prime} \mathrm{N}$ y 99011'16.1" W Altitud: $2290 \mathrm{msnm}$.

Acceso: Libre para peatones, controlado por puesto de vigilancia para vehículos, en particular los domingos y días festivos. Los sitios dentro del CEPE pueden visitarse sólo durante días hábiles.

\section{Interés y valores:}

- Geológico: corte transversal de un lóbulo de lava de varias decenas de metros de longitud.

- Estratigráfico: Se aprecia el paleosuelo por debajo del lóbulo de lava.

- Arqueológico: fragmentos de cerámica en paleosuelo debajo de la lava.

Deportivo: paredes de lava usadas para práctica de escalada.

Descripción: En este sitio se expone un corte lateralmente extenso (Figura 7A) a través del campo de lava constituido aquí de un solo lóbulo, con superficie casi plana (sheet lobe) de un espesor de aproximadamente $5 \mathrm{~m}$. El interés particular del sitio radica en: 1) la exposición de la estructura vertical del flujo de lava marcada principalmente por cambios en la vesicularidad de la roca (Figuras 7B y 7C), y 2) la presencia de suturas (suture zones) que representan la zona de contacto lateral entre dos lóbulos que crecieron al mismo tiempo, finalmente fusionando en un solo lóbulo (Figuras 7D y 7E). Estas dos características pueden ser vistas en otros sitios (Cantera Pumas y Jardín botánico) pero están particularmente bien expuestas en este lugar. Pueden ser encontradas también en las canteras de la zona de IsidroFabela. Ambas características (estructura vertical y zonas de suturas) son típicas de lavas de tipo pahoehoe que crecen por un proceso de inflación sobre pendientes poco pronunciadas (Self et al., 1998). Las zonas de suturas habían llamado la atención de varios de los primeros autores de trabajos sobre la lava y habían sido interpretadas como tubos de explosión (Waitz y Wittich, 1910; Badilla-Cruz, 1977). Walker (2009) interpreta estas estructuras como resultados de los procesos de emplazamiento de los flujos. 

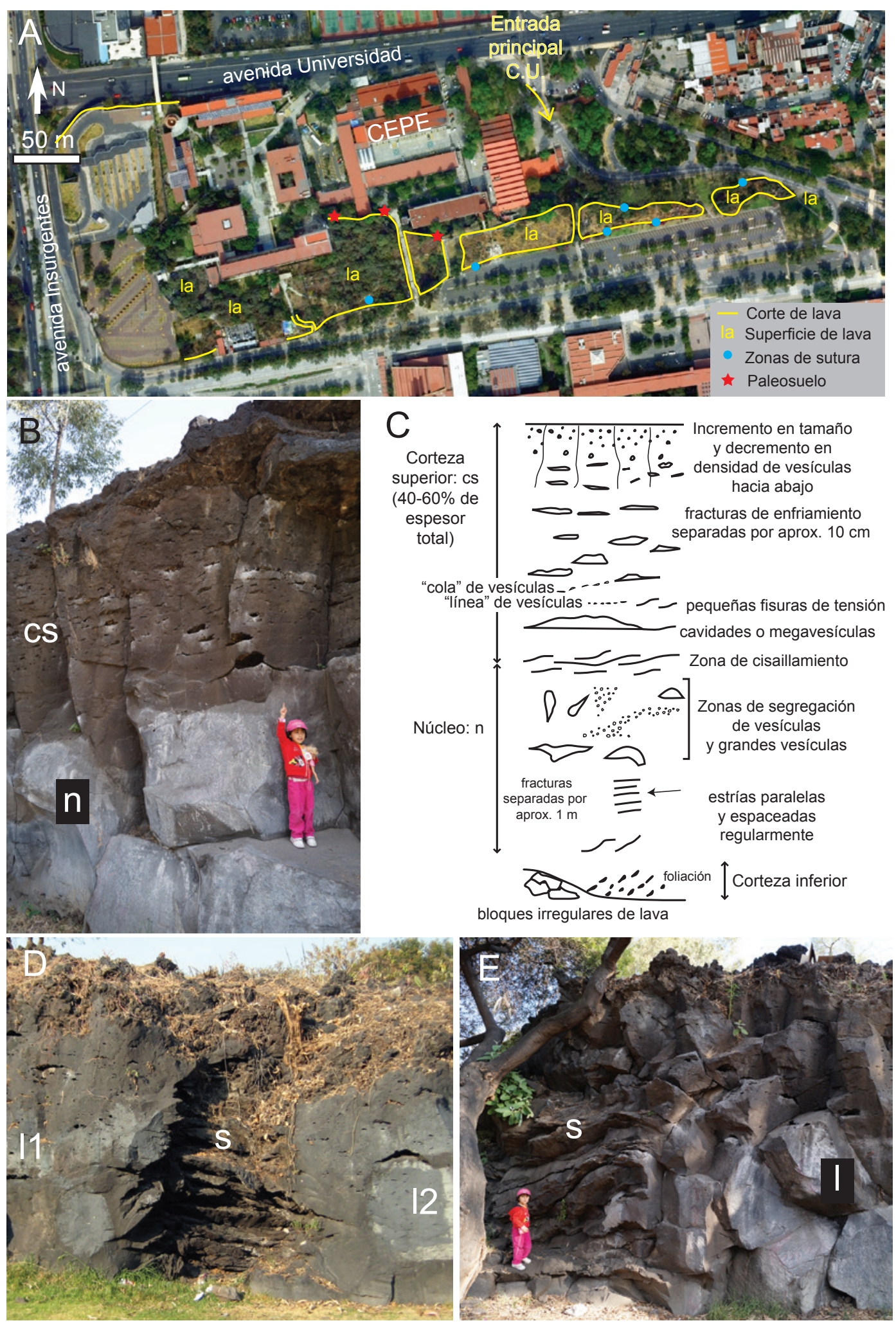

Figura 7. Sitio Entrada principal de Ciudad Universitaria y el Centro de Enseñanza para Extranjeros (CEPE) (ID 5). A. Ubicación de sitios y avenidas cercanas sobre imagen satelital de Google Earth (obtenida en septiembre 4 de 2013, consultada en línea en agosto de 2015). Los sitios donde aparece el contacto entre la base del flujo y el paleosuelo (estrellas rojas) se ubican dentro de las instalaciones del CEPE. B. Corte a través del flujo, se distingue el núcleo denso de color gris claro $(\mathrm{N})$ y la parte superior vesicular (CS: corteza superior) de color gris oscuro. La diferencia de color se relaciona con la porosidad de la roca que permite la infiltración de agua solamente en la parte superior vesicular. C. Esquema de las características de las burbujas y fracturas (joints) en las tres zonas principales de la colada (corteza superior, núcleo y corteza inferior). Un esquema parecido fue publicado por Walker (1993; Fig. 8a). D. Zona de sutura (S) en dos lóbulos: L1 y L2. Nótese la estructura vesicular de los lóbulos. E. Zona de sutura (S) más amplia en sitio cercano. La zona es marcada por la superposición de láminas de roca curveadas con superficies estriadas que conectan directamente al interior del flujo (L). 
En el interior del CEPE (en la parte posterior del auditorio, estrellas rojas en Figura 7A), puede apreciarse un paleosuelo cubierto por el flujo lávico; posee una coloración que varía de café obscuro a anaranjada con una consistencia de material desde nada consolidado hasta endurecido, respectivamente (se puede apreciar una secuencia similar en el sitio Campo de beisbol, que se describe más adelante). El endurecimiento y coloración naranja del suelo se debe al fuerte calentamiento sufrido por el suelo en contacto directo con la lava fluida. El paleosuelo contiene fragmentos de cerámica antiguos indicativos de la presencia humana en la zona, previa a la erupción (González et al., 2000). El fechamiento del paleosuelo debajo de la parte "quemada" dio aproximadamente 2300 AP, una edad distintivamente más antigua que la edad de carbón encontrado dentro del mismo deposito de ceniza en otros sitios (González et al., 2000; Siebe, 2000). En el contacto entre la base de la lava y el paleosuelo puede apreciarse una capa de ceniza fina que alcanza localmente $10 \mathrm{~cm}$ de espesor, y está relacionada con un episodio temprano explosivo del volcán.

En este mismo sitio se pueden observar a simple vista algunos cristales blancos dentro de la colada, que corresponden a "xenocristales" o cristales ajenos al magma, que fueron incorporados por él durante su ascenso a través de la corteza continental. Cristales más pequeños dentro de la lava tienen una forma semi-redonda y un color verde claro característicos, que corresponden a olivinos (ricos en magnesio y hierro que son estables a altas temperaturas).

Conservación: En general se encuentra bien conservado, sobre todo en el caso del afloramiento ubicado en el CEPE.

ID 6: Paleosuelo del Campo de beisbol

Ubicación: Cerca del campo de beisbol ubicado dentro de CU, a un lado de avenida de Los Insurgentes. Otros afloramientos parecidos se encuentran cerca de los cruces entre el circuito interior de Ciudad Universitaria y avenida de Los Insurgentes.

Coordenadas geográficas: B: $19^{\circ} 19^{\prime} 28.7^{\prime \prime} \mathrm{N}$ y 99 $11^{\prime} 23.0^{\prime \prime}$ W; C: 19²19'30.9" N y 99²1'29.3" W

Altitud: B: 2299 msnm; C: $2281 \mathrm{msnm}$

Acceso: Por el circuito interior de Ciudad Universitaria. Interés y valores:

- Estratigráfico: afloramiento de paleosuelo por debajo de la lava.

- Arqueológico: fragmentos de cerámica en paleosuelo debajo de la lava.

Descripción: En este sitio aflora la base de las lavas y su contacto con el suelo pre-existente (paleosuelo); se compone de dos sitios. En el primer sitio (B en Figura 8A) los flujos de lava alcanzan aproximadamente $4 \mathrm{~m}$ de espesor y reposan sobre un paleosuelo localmente endurecido de color anaranjado debido a su calentamiento por las lavas (Figura $8 \mathrm{~B})$. Una delgada capa ( $<5 \mathrm{~cm}$ de espesor) de ceniza fina estratificada puede ser observada localmente entre la base de la lava y el paleosuelo. En el segundo sitio ubicado detrás de una sub-estación eléctrica (C en Figura 8A), aflora una parte de la paleotopografía. Se compone, del techo a la base, de una capa de ceniza de $3 \mathrm{~cm}$ de espesor, un paleosuelo de $40 \mathrm{~cm}$ de espesor, y un depósito burdamente estratificado de $1.4 \mathrm{~m}$ de espesor compuesto de bloques angulares en una matriz fina (b y c en Figura $8 \mathrm{C}$ ). Este último probablemente se originó por la movilización y transporte de bloques de lava por un flujo de agua y sedimentos (lahar). Como en el sitio descrito en el CEPE, se han encontrado vestigios arqueológicos (cerámica) en el paleosuelo debajo de la lava. Conservación: Estos sitios ( $\mathrm{B}$ y $\mathrm{C}$ ) no reciben medidas particulares de preservación (no son parte de la reserva) y por lo tanto podrían llegar a desaparecer ante el desarrollo de infraestructura dentro de la Ciudad Universitaria.

3.3. Geositios ubicados en áreas vecinas fuera del campus de Ciudad Universitaria

ID 7: Cuicuilco: Pirámide (Zona arqueológica de Cuicuilco) y lavas almohadilladas en el Centro Comercial (Plaza Cuicuilco o Loreto-Peña Pobre)

Ubicación: A un costado de la avenida Los Insurgentes, cerca de su cruce con Periférico Sur, en dirección sur a norte. Coordenadas geográficas: $19^{\circ} 18^{\prime} 5.87^{\prime \prime} \mathrm{N}$ y $99^{\circ} 10^{\prime} 53.82^{\prime \prime} \mathrm{W}$ (Pirámide), 19²1'56.2" N y 99¹0'57.25" W (Lavas almohadilladas en centro comercial).

Altitud: $2300 \mathrm{msnm}$

Acceso: Pirámide: Controlado, cuenta con estacionamiento, sitio vigilado, puede visitarse todos los días de 9 a 17 horas, el acceso es libre. Centro Comercial: Afloramiento situado aproximadamente a $500 \mathrm{~m}$ de la zona arqueológica de Cuicuilco, dentro del estacionamiento techado del centro comercial "Plaza Cuicuilco".

\section{Interés y valores:}

- Vulcanológico: estructuras superficiales y cortes verticales, lavas almohadilladas.

- Estratigráfico y ambiental: cuerpo de agua pre-eruptivo, contacto de lava con paleosuelo.

- Arqueológico: presencia de estructuras, destacando la pirámide de Cuicuilco. El museo de sitio (M en Figura 9A) presenta algunos artefactos encontrados durante las excavaciones.

\section{Descripción:}

Pirámide:

Este sitio de interés principalmente arqueológico (uno de los centros urbanos más antiguos en México y de la cuenca de México) fue descubierto en 1922 (Cummings, 1926) y transformado en 1985 en parque arqueológico. $\mathrm{Su}$ existencia indica la presencia de un centro de población en el Valle de México contemporáneo a la erupción del volcán Xitle. Como efecto de la erupción se produce la migración de su población hacia el centro de Teotihuacán, $55 \mathrm{~km}$ al noreste, con el consiguiente desarrollo de este sitio como el más grande de este periodo en América, aunque fechamientos recientes indican que la erupción podría haber ocurrido varios siglos después del abandono de Cuicuilco y crecimiento en la expansión de Teotihuacán (Siebe, 2000). 

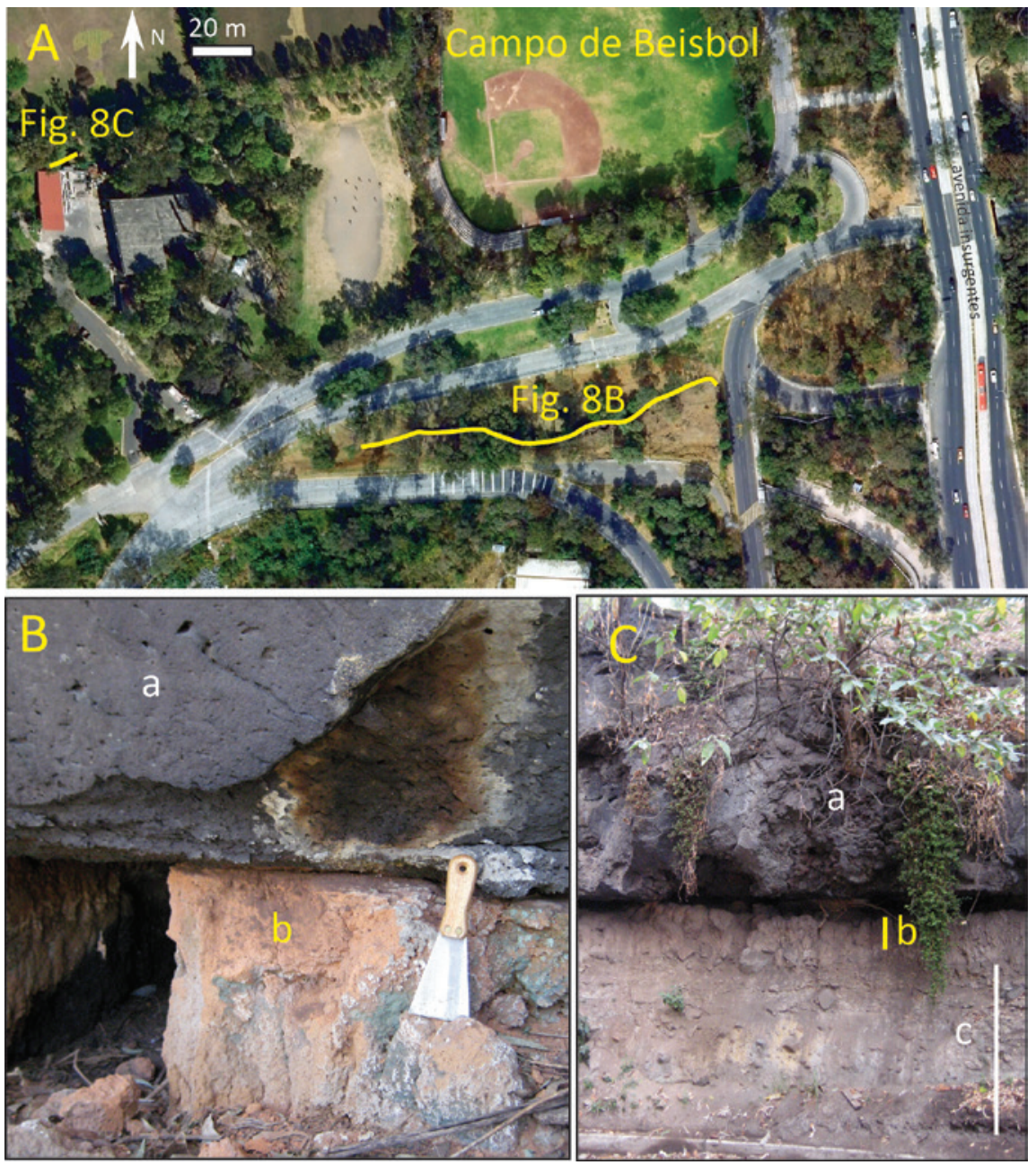

Figura 8. Sitio Campo de Beisbol (ID 6). A. Ubicación del sitio en imagen satelital (Google Earth, obtenida en septiembre 4 de 2013, consultada en línea en agosto de 2015), próximo a la avenida Insurgentes. El contacto entre las lavas y los depósitos preexistentes puede ser examinado en varias otras localidades en la proximidad, en cortes a lo largo de los accesos que cruzan por debajo de la avenida. B. Contacto de las lavas (a) sobre depósitos volcanoclásticos (b) con paleosuelo (b) intermedio. C. Contacto de lavas (a) sobre paleosuelo endurecido y rojizo (b). Nótese la vesicularidad de la base de los flujos (corteza inferior). Las características atípicas del paleosuelo se atribuyen al efecto de calor en la base de los flujos de lava.

La entrada del sitio arqueológico se compone de un camino empedrado ancho, que cruza las lavas para llegar a la base de la pirámide (Figura 9A). A lo largo de este camino de acceso, así como por otros caminos acondicionados dentro del campo de lava (líneas blancas punteadas en Figura 9A), se puede observar la superficie irregular de las lavas constituidas de una sucesión de lóbulos inter-conectados, formando Tumuli y lava rises (ver descripción sitio Jardín botánico). Los lóbulos muestran fracturas abiertas de hasta 2 a $3 \mathrm{~m}$ de profundidad que exponen una corteza vesicular estratificada.

Desde la cima de la pirámide y a lo largo del camino que la circunda, se puede observar en varios puntos el contacto entre la lava y el substrato antiguo representado, dependiendo del sitio, por construcciones antiguas (Figura 9B), un flujo de lava más antiguo (Figura 9C), o un paleosuelo (Figura 9D). El contacto esta marcado por la presencia de ceniza fina (Cummings, 1926) probablemente producida por actividad explosiva al inicio de la erupción (Siebe, 2000). Desde la cima de la Pirámide se pueden ver varios conos recientes de la Sierra Chichinautzin, el cono del Xitle, el estratovolcán Ajusco en un segundo plano, así como otros sitios como el Cerro Zacayucan, dentro del vecino Bosque de Tlalpan y el Cerro de Zacatépetl, ambos rodeados por las lavas del Xitle. En condiciones óptimas de visibilidad, pueden apreciarse también los volcanes Popocatépetl y Iztaccíhuatl al oriente.

Centro Comercial:

Su principal interés geológico es el afloramiento de lavas almohadilladas bien representadas (pillow lavas, Figura 9E). Estas tienen una forma redondeada con estrías en la superficie, característica de la deformación plástica de la costra exterior de los lóbulos de lava, enfriada rápidamente al contacto con el agua. Su presencia es la prueba quizás más contundente de la existencia de un cuerpo de agua en esta zona al momento del emplazamiento de las lavas (Delgado 

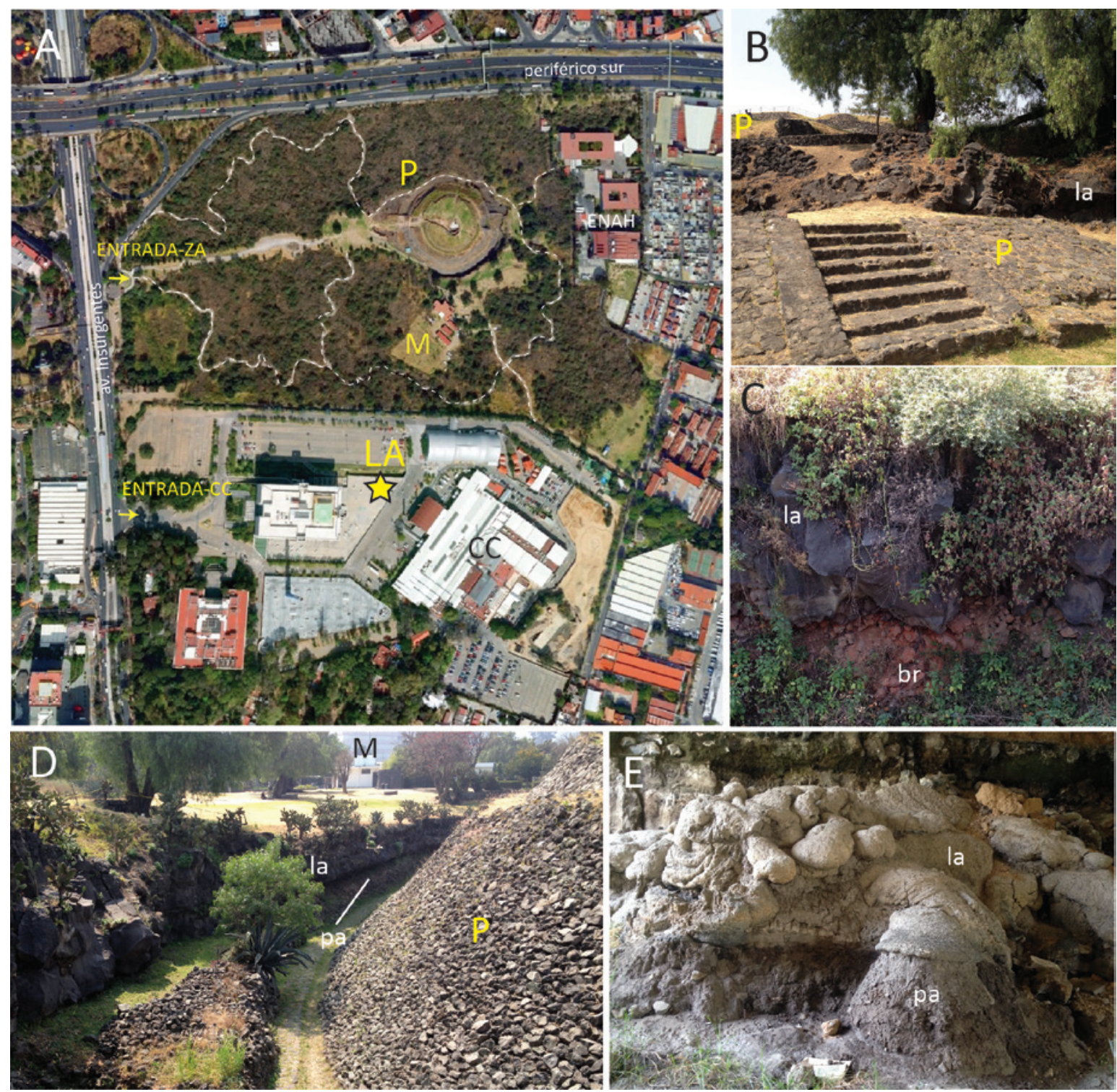

Figura 9. Sitio Cuicuilco (ID 7). A. Imagen satelital (Google Earth, obtenida en septiembre 4 de 2013, consultada en línea en agosto de 2015) con la ubicación de los sitios de la pirámide (P) dentro de la Zona Arqueológica (ZA), y de las lavas almohadilladas (LA) dentro del Centro Comercial (CC) con sus entradas respectivas. Museo (M), el sitio en la Zona Arqueológica. B: Contacto entre las lavas (la) y la pirámide (P). Las lavas miden un metro de espesor como máximo. C. Oxidación del material fragmentado (bloques rojos: br) ubicado justo debajo de la lava (la) - afloramiento ubicado del lado este de la Pirámide; flujos de lava de $1.5 \mathrm{~m}$ de espesor aproximado. D. Contacto de la lava con el paleosuelo, a poca distancia de la Pirámide. Vista hacia el museo (M). E. Lavas almohadilladas (la) con texturas cordadas y abombadas típicas, cubriendo paleosuelo lacustre (pa) en sitio del centro comercial. Espesor de lava aproximado de $1 \mathrm{~m}$.

et al., 1998). Cerca de este lugar se han encontrado también espesas secuencias sedimentarias lacustres (González et al., 2000; Lugo-Hubp et al., 2001). Ambas observaciones concuerdan con la idea que Cuicuilco, antes de la erupción, estaba ubicado en una planicie deltaica al pie de las faldas más distantes del estratovolcán Ajusco.

Conservación: Pirámide: Toda vez que se trata de un área de acceso restringido el sitio se encuentra bien conservado. Centro Comercial: El sitio es bien preservado y vigilado, aunque sin valoración; se requiere de autorización para la toma de fotografías.
ID 8: Parque Nacional Bosque del Pedregal o "Bosque de Tlalpan"

Ubicación: Sobre Avenida Santa Teresa, a poca distancia del cruce de Periférico sur y Avenida de Los Insurgentes.

Coordenadas geográficas: $19^{\circ} 17^{\prime} 47.27^{\prime \prime} \mathrm{N}$ y $99^{\circ} 11^{\prime} 32.25^{\prime \prime}$ W (entrada)

Altitud: $2317 \mathrm{msnm}$.

Acceso: Periférico, salida "Parque Nacional del Pedregal", o por Insurgentes sur.

\section{Interés y valores:}

- Geológico: lavas del Xitle con morfología tipo aa; depósitos de pómez y lahares de proveniencia incierta. 
- $\quad$ Estratigráfico: contactos diversos y paleosuelos.

- Histórico: antiguamente parte de la Hacienda de Peña Pobre.

- Ecológico: lugar de captación de agua pluvial; presencia de múltiples pozos.

- Deportivo y ocio: zona de recreación, pista para correr y caminos acondicionados para paseos.

Descripción: El "Parque Nacional Bosque del Pedregal" o Bosque de Tlalpan , y antiguamente "Cerro de Zacayucan" es una zona boscosa, establecida sobre antiguos cerros rodeados y cubiertos parcialmente por la lava del Xitle (Figura 10A). Estos terrenos formaron parte de la Hacienda de Peña Pobre, propietaria de la fábrica de papel de Loreto y Peña Pobre (Lenz, 2010 y comunicación personal), actualmente convertida en el centro comercial de "Plaza Cuicuilco". La fábrica usó los terrenos del actual bosque para la plantación de árboles, en particular eucaliptos, que todavía forman parte de la cubierta forestal en esta parte y varias otras del sur de la Ciudad de México. En la década de los años 1970 una porción de los terrenos fue adquirida por el gobierno de la ciudad para ser convertida en un parque recreativo y deportivo. Dentro del parque se encuentran varios pozos de agua potable.

Las lavas del Xitle cubren una parte importante del parque (Figura 2). Estas desarrollan aquí una superficie fragmentada tipo transicional o aa, la que prevalece en la parte más proximal del campo de lava. Aunque varios factores pueden ser involucrados (incremento en tasa de emisión o en la "cristalinidad" de la lava), la fuerte inclinación del terreno en esta parte puede explicar la superficie fragmentada de los flujos y la formación local de canales de lava (a en Figura 10A).

El punto más elevado del bosque corresponde al Cerro de Zacayucan; se trata de un volcán antiguo (quizás un cono de escoria) rodeado por las lavas (b en Figura 10A) y cubierto por varios metros de suelo y un espeso depósito de pómez blanca (Figuras 10B y 10C). La proveniencia de esta pómez es incierta pero podría relacionarse con la actividad reciente de volcanes más al sur de la Sierra de Las Cruces (Cerro San Miguel, José Luis Arce, comunicación personal).
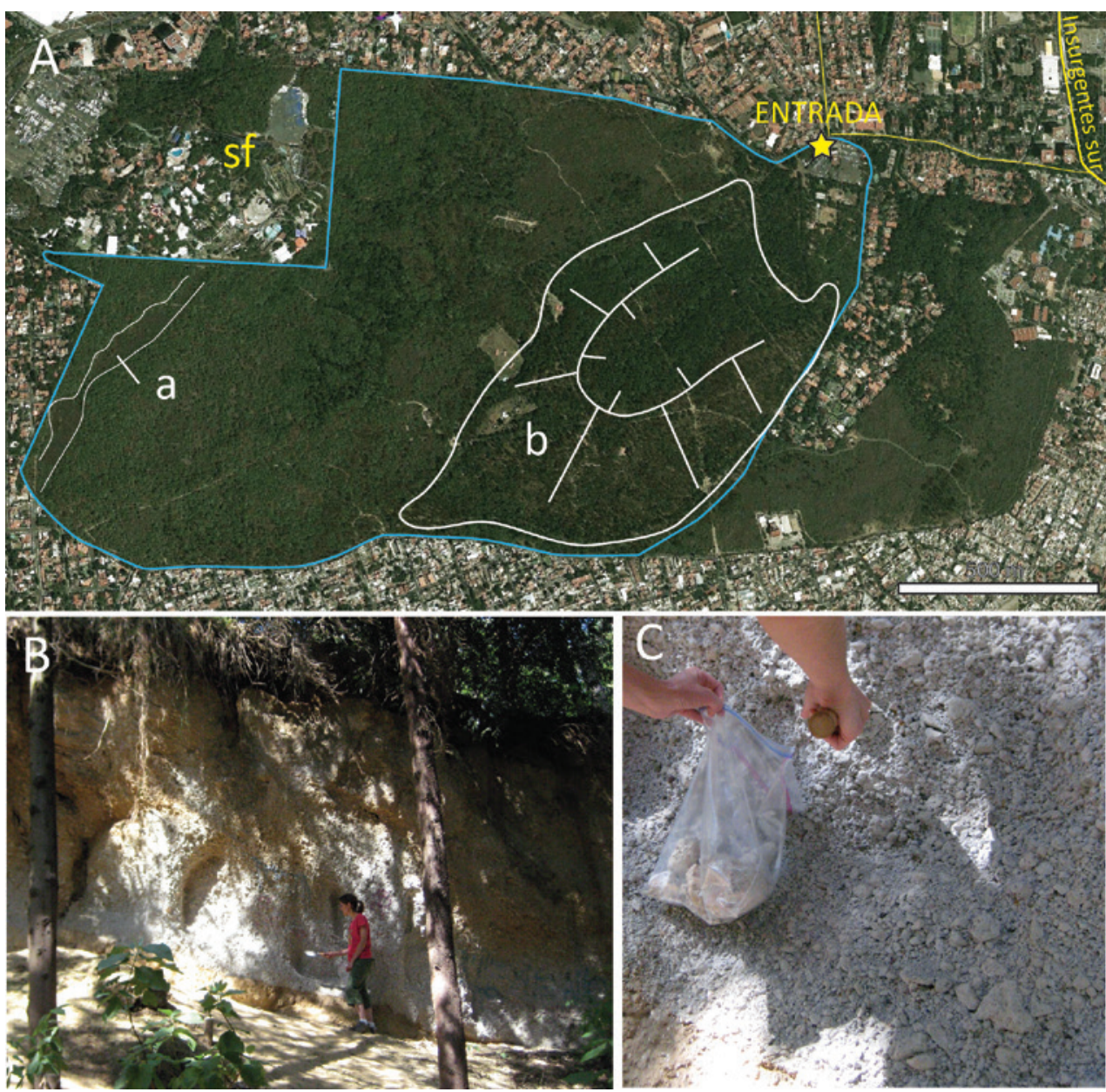

Figura 10. Sitio del Bosque de Tlalpan (ID 8). A. Imagen satelital (Google Earth, obtenida en septiembre 4 de 2013, consultada en línea en agosto de 2015); SF: parque de atracción Six Flags, a: Canal de lava; b: antiguo volcán rodeado por las lavas del Xitle. B. Depósito de caída, rico en fragmentos de pómez blanca, aflorando en el bosque, sobre las laderas del antiguo volcán. C. Detalle de la parte inferior del depósito de pómez, mostrando el grosor de los fragmentos, lo cual indica una fuente próxima. 
Conservación: Este sitio se encuentra en buen estado de conservación, aunque se requiere una modernización de los mapas y letreros dentro del parque para facilitar una buena orientación de las personas. Algunos problemas de seguridad han sido reportados en las áreas más altas y más lejanas a la entrada principal.

ID 9: Volcán Xitle

Ubicación: Sierra Chichinautzin, a 5 km al NE del Volcán Ajusco.

Coordenadas geográficas: $19^{\circ} 14^{\prime} 50.4^{\prime \prime} \mathrm{N}$ y 99² $13^{\prime} 19.2^{\prime \prime} \mathrm{W}$ Altitud: $3150 \mathrm{msnm}$.

Acceso: Camino al Ajusco que conecta al Periférico sur. Interés y valores:

- Geológico: centro emisor de las lavas.

- Geomorfológico: morfología del volcán.

Descripción: El volcán Xitle (o Xictle) forma un cono de ceniza y escoria de $200 \mathrm{~m}$ de alto, con un cráter de $50 \mathrm{~m}$ de profundidad. Existen actualmente dos caminos de acceso al cráter: uno por el lado este, y otro por el lado oeste (a y b en Figura 11A). El camino parte de la base del cono principal donde se puede observar una secuencia de escoria y bombas provenientes del cono. Las lavas que afloran al este del cono tienen una cobertura vegetal escasa y un suelo poco desarrollado. Siguiendo el camino desde el punto a) hacia las lavas, se pueden apreciar varias entradas de tubos y estructuras de colapso (skylights) dentro de las mismas (c en Figura 11A). Cabe mencionar que varios sistemas de tubos han sido encontrados dentro de las lavas del Xitle (Schmitter, 1953), los más grandes (hasta $30 \mathrm{~m}$ de ancho) forman el sistema de Padierna (Martin del Pozzo et al., 1997). Sin embargo, a pesar de su interés científico, turístico y educacional, muchos de estos tubos han sido cerrados por cuestiones de seguridad.

El b) sube a partir de una zona poblada y pasa por una estación de bomberos encargada de la vigilancia de fuegos en el área de bosque (d en Figura 11A). La estación está establecida en el borde de una estructura cónica (Xicontle) alineada con el cono principal en una dirección oeste (XI en Figura 11A). Esta estructura está compuesta de una superposición de flujos de lava truncada por una depresión en su parte central. Esta estructura pudo haberse formado por la acumulación de lava desgasificada a lo largo de la boca eruptiva y el drenaje de su parte central hacia el fin de la erupción.

Los dos caminos mencionados permiten llegar al borde del cráter del cono principal y lo rodean. De allí, se observa que el borde sur del cráter es $50 \mathrm{~m}$ más alto que el borde norte (Figura 11B), probablemente indicando la dirección predominante del viento durante su fase constructiva. Desde la parte más alta del cráter se puede observar hacia el sur el estratovolcán del Ajusco que sufrió un colapso mayor en su flanco norte, en un tiempo desconocido antes de la erupción del Xitle y rasgos derivados de la erosión durante el último periodo glacial. Hacia el norte se aprecia la parte sur de la ciudad de México y la gran distancia que
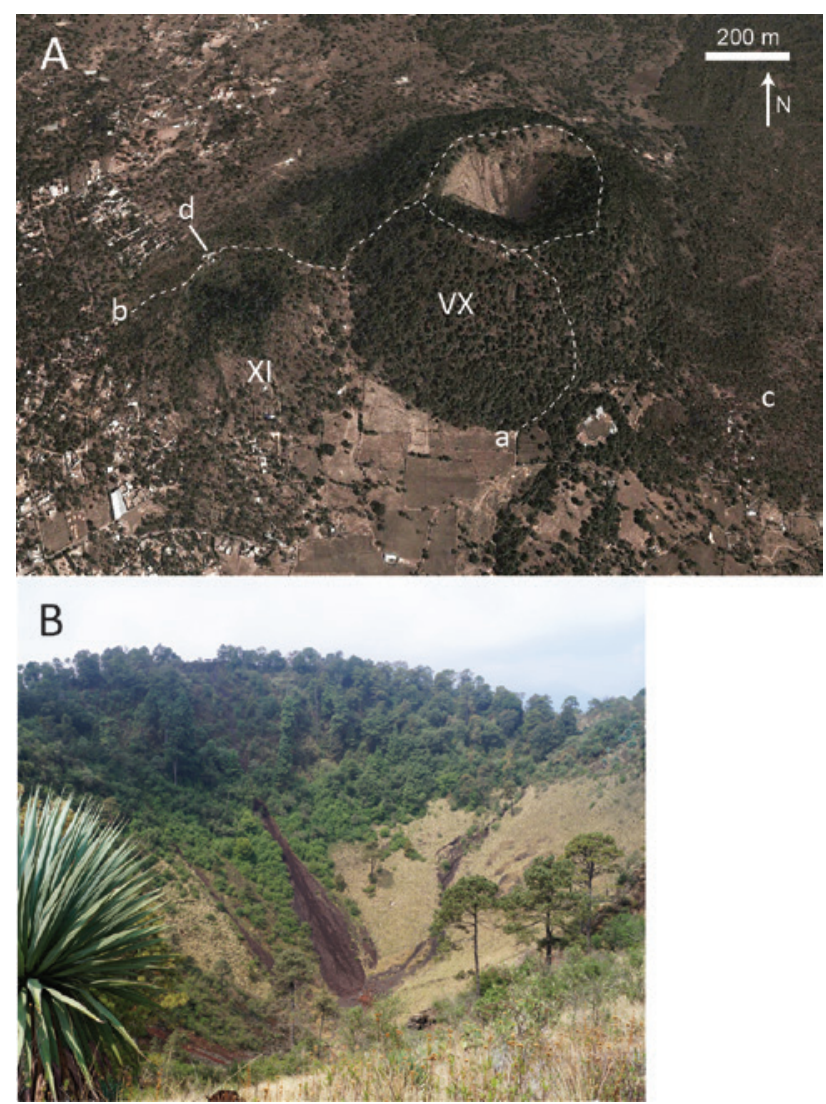

Figura 11. Sitio del Volcán Xitle (ID 9). A. Imagen satelital (Google Earth, obtenida en septiembre 4 de 2013, consultada en línea en agosto de 2015); VX: cono principal del volcán; a y b, puntos de inicio de los dos caminos para llegar a la cima del cono principal; c: área con tubos de lava en flujos emplazados después de la formación del cono principal (ausencia de cobertura por piroclastos del cono); d: estación de bomberos ubicada en el borde del cráter del Xicontle (XI), estructura lávica formada hacia el fin de la erupción. B. Vista del fondo del cráter del cono principal desde el borde norte. Nótese la mayor elevación del borde sur del cono, lo cual puede reflejar la dirección principal del viento durante la construcción del cono.

las lavas alcanzaron (se distingue al campus de la UNAM en condiciones de buena visibilidad).

Conservación: El sitio se encuentra bien conservado aunque prevalecen problemas de seguridad en la zona.

\section{Discusión y conclusiones}

De manera conjunta, los geositios seleccionados permiten identificar valores geológicos, geomorfológicos y adicionales, que sintetizan la evolución de este sector de la cuenca y su interacción con la zona urbana de la Ciudad de México. Resulta paradójico que comúnmente sean los valores adicionales no geológicos los que mayor atención han recibido, no obstante el control que ejerce el sustrato geológico sobre ellos, lo que se contradice con el alto potencial que poseen los geositios seleccionados como herramientas para la divulgación del patrimonio geológico 
al público en general. Estos sitios también poseen un alto potencial pedagógico derivado de la exposición de las lavas del volcán Xitle, considerado a la fecha como el más joven de la Sierra Chichinautzin, y por su excepcional grado de conservación dada la juventud del fenómeno, cuya integridad, sin embargo, se encuentra en algunos casos profundamente modificada y en otros amenazada dada su ubicación dentro de la mancha urbana de la ciudad. Algunos de estos sitios, producto de las modificaciones de origen antrópico (canteras y otros cortes o perfiles), permiten, sin embargo, apreciar y describir la evolución y características de los derrames y los flujos que lo componen, que de haber mantenido su integridad original no serían apreciables.

Desde el punto de vista pedagógico, los geositios seleccionados son ejemplos representativos que poseen un alto valor para comprender la evolución del fenómeno volcánico presente en la zona. No es de menor interés, la valoración y promoción de los sitios vistos como herramientas potenciales para divulgar aspectos relativos a los peligros y riesgos de carácter volcánico entre la población general. En este sentido, las formas volcánicas derivadas de fenómenos recientes y su relación con la sociedad (caso sitio arqueológico Cuicuilco) representan ejemplos claros y representativos, que en zonas volcánicas más antiguas serían difíciles de ser apreciadas. Así mismo, para los objetivos de la REPSA, constituyen un acervo de información necesario que debe valorarse y promoverse como parte de su oferta educativa, tanto formal (como parte de la oferta curricular universitaria) como informal (desde el punto de vista de la promoción de las Ciencias de la Tierra, en particular de la geología y la geomorfología), entre el público general. Este trabajo contribuye, en este sentido a la promoción de este rico patrimonio geológico y geomorfológico dentro de las estrategias de divulgación tanto de la propia REPSA como de los geositios ubicados fuera de la misma, incluyendo letreros informativos específicos de estos rasgos.

Si bien, en lo general, la integridad de los geositios referidos se encuentra relativamente asegurada dentro de las zonas protegidas sujetas a algún tipo de control, debe asegurarse que aquellos sitios que no se encuentran en dicha condición sean protegidos para preservar sus características. En este sentido, la información que aquí se proporciona puede ser considerada dentro de los planes de obras y ampliación de infraestructura, en particular dentro de la Ciudad Universitaria.

\section{Agradecimientos}

Agradecemos al Dr. Claus Siebe por la información que nos proporcionó durante los últimos años sobre las lavas del Xitle. Se agradece también la colaboración de Alberto Heintz, quien proporcionó información e imágenes del Bosque de Tlalpan, al Ing. Jorge A. Gutiérrez Estrada por las facilidades otorgadas para visitar la cantera de los Pumas, al personal del Bosque de Tlalpan por su amable asistencia, y a José Antonio Santiago, Sergio Salinas, Julie Roberge y Stephen Self por su colaboración en el trabajo de campo. Felipe D. Guzmán amablemente tomó y proporcionó las fotografías del sitio de la Cantera de los Pumas. Este trabajo contó con el apoyo de la Dirección General de Apoyo al Personal Académico (DGAPA-UNAM), proyectos IN100714 (JLP) y IN105615 (MNG), así como del Consejo Nacional de Ciencia y Tecnología (CONACyT), proyecto 152294 (MNG).

\section{Referencias}

Alva-Valdivia, L.M., 2005, Comprehensive paleomagnetic study of a succession of Holocene olivine-basalt flow: Xitle Volcano (Mexico) revisited: Earth Planets Space, 57, 839-853.

Badilla-Cruz, R.R., 1977, Estudio petrológico de la lava de la parte noreste del Pedregal de San Ángel, D.F.: Boletín de la Sociedad Geológica Mexicana, 38, 40-57.

Cañón-Tapia, E., Walker, G.P.L., Herrero-Bervera, E., 1995, Magnetic fabric and flow direction in basaltic Pahoehoe lava of Xitle Volcano, Mexico: Journal of Volcanology and Geothermal Research, 65, 249-263.

Cañón-Tapia, E., Walker, G.P.L., Herrero-Bervera, 1996, The internal structure of lava flows-insights from AMS measurements I: Nearvent aa: Journal of Volcanology and Geothermal Research, 70, 21-36.

Cervantes, P., Molinero, R.J., 1995, Eventos volcánicos al Sur de la Ciudad de México: México DF, UNAM, Facultad de Ingeniería, tesis de licenciatura, $74 \mathrm{p}$.

Córdova, C., Martin del Pozzo, A.L., Camacho, J.L, 1994, Palaeolandforms and Volcanic Impact on the Environment of Prehistoric Cuicuilco, Southern Mexico City: Journal of Archaeological Science, 21, 585-596.

Comisión Sitios de Interés Geológico de la República Argentina (CSIGA), 2008, Sitios de Interés Geológico de la República Argentina: Buenos Aires, Comisión Sitios de Interés Geológico de la República Argentina, Instituto de Geología y Recursos Minerales, Servicio de Geología y Minería de la República Argentina, Anales 46, Tomo I 446 p, Tomo II $461 \mathrm{p}$.

Cummings, B., 1926, Cuicuilco and the Archaic culture of Mexico: Scientific Monthly, 23, 289-304.

De Kassner, L.S., 2009, El espacio escultórico: México, D.F., Universidad Nacional Autónoma de México, 206 p.

Delgado, H., Molinero, R., Cervantes, P., Nieto-Obregón, J., Lozano-Santa Cruz, R., Macías-González, H.L., Mendoza-Rosales, C., SilvaRomo, G., 1998, Geology of Xitle volcano in southern Mexico City, a 2000 year-old monogenetic volcano in an urban area: Revista Mexicana de Ciencias Geológicas, 15, 115-131.

Gaitán-Martínez, J., 2012, La Cantera Puma: Revista AAPAUNAM Academia, Ciencia y Cultura, 4, 321-326.

González, S., Pastrana, A., Siebe, C., Duller, G., 2000, Timing of the prehistoric eruption of Xitle Volcano and the abandonment of Cuicuilco Pyramid, Southern Basin of Mexico, en McGuire, W. J., Griffiths, D.R., Hancock, P.L., Stewart, I.S (eds), The archaeology of geological catastrophes: Geological Society of London Special publications, 171, 205-224.

Gray, M., 2004, Geodiversity: valuing and conserving abiotic nature: West Sussex, Wiley, $508 \mathrm{p}$.

Guilbaud, M.-N., Siebe, C., 2009, The lava flow-field of the $c a .1670$ yrs BP Xitle eruption, México: structure and implications for eruption dynamics (resumen), en Siebe, C., Guilbaud, M.N., Salinas, S., 250 Aniversario del nacimiento del volcán Jorullo en México: Morelia, Michoacán, México, 28-29.

Heizer, R.F., Bennyhoff, J.A., 1958, Archeological Investigation of Cuicuilco, Valley of Mexico, 1957: Science, 127, 232-233. 
Herrero-Bervera E., Urrutia-Fucugauchi, J., Martin del Pozzo, A.L., Böhnel, H., Guerrero, J., 1986, Normal amplitude bruhnes paleosecular variation at low-latitudes: A paleomagnetic record from the Trans-Mexican Volcanic Belt: Geophysical Research Letters, $13,1442-1445$

Hon, K., Kauahikaua, J., Denlinger, R., Mackay, K., 1994, Emplacement and inflation of pahoehoe sheet flows, Observations and measurements of active lava flows on Kilauea Volcano, Hawaii: Geological Society of America Bulletin, 106, 351-370.

Kauahikaua, L., Sherrod, D.R., Cashman, K.V., Heliker, C., Hon, K., Mattox, T.N., Johnson, J.A., 2003, Hawaiian lava flow dynamics during the Pu'u'O'o-Kupaianaha eruption: A tale of two decades, en Heliker, C., Swanson, D.A., Takahashi, T.J. (eds.), The Pu'u'O'oKupaianaha eruption of Kilauea volcano, Hawaii: The first 20 years: US Geological Survey Professional Paper, 1676, 63-88.

Lenz, K.A., 2010, Cerro de Zacayucan, actualmente Bosque de Tlalpan: Mexico, Mitt, No. 600, 20-24.

Libby W.F., 1955, Radiocarbon dating: EUA, University of Chicago Press, $184 \mathrm{p}$.

Lot-Helgueras A., 2008, 25 años de la Reserva Ecológica del Pedregal de San Ángel: Ciencias, 91, 30-32.

Lugo-Hubp, J., Inbar, M., Pastrana, A., Flores, A., Zamorano, J.J., 2001, Interpretation of the geomorphic setting of the Cuicuilco basin, Mexico City, affected by the pre-Hispanic eruption of the Xitle volcano: Géomorphologie: relief, processus, environnement, 3, 223-232.

MacDonald, G.A., 1953, Pahoehoe, aa and block lavas: American Journal of Science, 251, 169-191.

Martin del Pozzo, A.L., 1982, Monogenetic vulcanism in the Sierra Chichinautzin: Bulletin of Vulcanology, 45, 9-24.

Martin del Pozzo, A.L., Espinasa, R., Lugo, J., Barba, L., Lopez, J., Plunkett, P., Uruñela, G., Manzanilla, L., 1997, Volcanic impact in central Mexico, en Conferencia IAVCEI: Puerto Vallarta, México, guía de excursión, IAVCEI, 33 p.

Morales, J., Alva-Valdivia, L.M., Goguitchaichvili, A., Urrutia-Fucugauchi, J., 2006, Cooling rate corrected paleointensities from the Xitle lava flow: Evaluation of within-site scatter for single spot-reading cooling units: Earth Planets and Space, 58, 1341-1347.

Panizza, M., 2001, Geomorphosites: concepts, methods and examples of geomorphological survey: Chinese Science Bulletin, 46, 4-5.

Parsons, J.R., 1989, Arqueología regional en la Cuenca de México, una estrategia para la investigación futura: Anales de Antropología, 26, 157-257.

Reynard, E., Panizza, M., 2007, Geomorphosites: definition, assessment and mapping: Géomorphologie: relief, processus, environnement, 3, 177-180.

Sanders, W.T., Parsons, J.R., Santley, R.S., 1979, The Basin of Mexico: ecological processes in the evolution of a civilization: Nueva York, Academic Press, 561 p.

Schaaf, P., Siebe, C., Stimac, J., Macías, J.L., 2005, Geochemical evidence for mantle origin and crustal processes in volcanic rocks from Popocatepetl and surrounding monogenetic volcanoes, central Mexico: Journal of Petrology, 46, 1243-1282.
Schmitter, E., 1953, Investigación petrológica en las lavas del pedregal de San Angel, en Congreso Científico Mexicano, Memorias 3, 218-237.

Self, S., Keszthelyi, L., Thordarson, T., 1998, The importance of pahoehoe: Annual Review of Earth and Planetary Science, 26, 81-110.

Siebe, C., 2000, Age and archaeological implications of Xitle volcano, southwestern Basin of Mexico-City: Journal of Volcanology and Geothermal Research, 104, 45-64.

Siebe, C., Rodríguez-Lara, V., Schaaf, P., Abrams, M., 2004, Geochemistry, $\mathrm{Sr}-\mathrm{Nd}$ isotope composition, and tectonic setting of Holocene Pelado, Guespalapa, and Chichinautzin scoria cones, south of Mexico City: Journal of Volcanology and Geothermal Research, 130, 197-226.

Swinamer, R.T., 1989, The Geomorphology, petrography, geochemistry and petrogenesis of the volcanic rocks in the Sierra Chichinautzin, Mexico: Ontario, Canadá, Queen's University, Kingston, tesis de maestría, $212 \mathrm{p}$.

Waitz, P., Wittich, E., 1910, Tubos de explosión en el Pedregal de San Angel: Boletín de la Sociedad Geológica Mexicana, 7, 169-186.

Walker, G.P.L., 1991, Structure, and origin by injection of lava under surface crust, of tumuli, "lava rises", "lava-rise pits", and "lavainflation clefts" in Hawaii: Bulletin of Volcanology, 53, 546-558.

Walker, G.P.L., 1993, Basaltic-volcano systems: Geological Society of London Special Publications, 76, 3-38.

Walker, G.P.L., 2009, The endogenous growth of pahoehoe lava lobes and morphology of lava-rise edges, en Thordarson, T., Self, S., Larsen, G., Rowland, S.K., Hoskudsson, A. (eds.), Studies in Volcanology: The Legacy of George Walker, Special Publications, IAVCEI, 2, 17-32.

Wallace, P.J., Carmichael, I.S.E., 1999, Quaternary volcanism near the Valley of Mexico: implications for subduction zone magmatism and the effects of crustal thickness variations on primitive magma compositions: Contributions to Mineralogy and Petrology, 135, 291-314.

Wiedenbein, F.W., 1994, Origin and use of the term 'geotope' in Germanspeaking countries, en O'Halloran, D., Harley, M., Knill, J. (eds.), Geological and Landscape Conservation: Geological Society of London, 117-120.

Wimbledon, W. A. P., Ishchenko, A.A., Gerasimenko, N.P., Karis, L.O., Suominen, V., Johansson, C.E., Freden, C., 2000, Geosites -an IUGS initiative: science supported by conservation, en Barettino, D., Wimbledon, W.A.P., Gallego, E. (eds.), Geological Heritage: Its Conservation and Management: Madrid, Instituto Tecnológico Geominero de España, 69-94.

Wittich, E., 1919, Los fenómenos microvolcanicos en el pedregal de San Angel: México, Memorias de la Sociedad Cientifica Antonio Alzate, 38, 101-120.

Manuscrito recibido: Febrero 2, 2014.

Manuscrito corregido recibido: Junio 26, 2014.

Manuscrito aceptado: Agosto 14, 2014. 